\title{
Preventing Illegitimate Extrasynaptic Acetylcholine Receptor Clustering Requires the RSU-1 Protein
}

\author{
Marie Pierron, Bérangère Pinan-Lucarré, and Jean-Louis Bessereau \\ Institut NeuroMyoGene, Université Claude Bernard Lyon 1, Centre National de la Recherche Scientifique, Unité Mixte de Recherche 5310, Institut National \\ de la Santé et de la Recherche Médicale U1217, 69622 Villeurbanne, France
}

Diffuse extrasynaptic neurotransmitter receptors constitute an abundant pool of receptors that can be recruited to modulate synaptic strength. Whether the diffuse distribution of receptors in extrasynaptic membranes is a default state or is actively controlled remains essentially unknown. Here we show that RSU-1 (Ras Suppressor-1) is required for the proper distribution of extrasynaptic acetylcholine receptors (AChRs) in Caenorhabditis elegans muscle cells. RSU-1 is an evolutionary conserved cytoplasmic protein that contains multiple leucine-rich repeats (LRRs) and interacts with integrin-dependent adhesion complexes. In rsu-1 mutants, neuromuscular junctions differentiate as in the wild type, but AChRs assemble into ectopic clusters that progressively enlarge during development. As a consequence, the synaptic content of AChRs is reduced. Our study provides the first evidence that an RSU-1-dependent active mechanism maintains extrasynaptic receptors dispersed and indirectly regulates synapse maturation.

Key words: acetylcholine receptor; C. elegans; forward genetic screen; neuromuscular junction; RSU-1; synapse

\section{Significance Statement}

Using Caenorhabditis elegans neuromuscular junction as a model synapse, we uncovered a novel mechanism that regulates the distribution of acetylcholine receptors (AChRs). In an unbiased visual screen for mutants with abnormal AChR distribution, we isolated the ras suppressor 1 ( $r s u-1)$ mutant based on the presence of large extrasynaptic clusters. We show that disrupting $r s u$ - 1 causes spontaneous clustering of extrasynaptic receptors that are normally dispersed, independently of synaptic cues. These clusters outcompete synaptic domains and cause a decrease of synaptic receptor content. These results indicate that the diffuse state of extrasynaptic receptors is not a default state that is simply explained by the lack of synaptic cues but necessitates additional proteins to prevent spontaneous clustering, a concept that is relevant for developmental and pathological situations.

\section{Introduction}

Ionotropic neurotransmitter receptors concentrate at synaptic sites close to presynaptic neurotransmitter release sites. The steady-state receptor clustering results from a dynamic equilibrium between synaptic and extrasynaptic receptors (Triller and Choquet, 2005). However, these extrasynaptic receptors are difficult to detect by conventional imaging because they are present at low density, al-

\footnotetext{
Received Oct. 8, 2015; revised April 15, 2016; accepted May 6, 2016.

Author contributions: M.P., B.P.-L., and J.-L.B. designed research; M.P., B.P.-L., and J.-L.B. performed research; M.P., B.P.-L., and J.-L.B. analyzed data; M.P., B.P.-L., and J.-L.B. wrote the paper.

The authors declare no competing financial interests.

M.P. was supported by the Neuropole Francilien and by the Association pour la Recherche contre le Cancer. This work was funded by Agence Nationale de la Recherche Grant ANR-11-BSV4-019, the Association Française contre les Myopathies, the Fédération pour la Recherche sur le Cerveau, and the Programme Avenir Lyon Saint-Etienne. We are grateful to Pablo Ibáñez-Cruceyra and Laura Pierson who built pIP1302B and pKG156 vectors, respectively. Some strains were provided by the Caenorhabditis Genetics Center, which is supported by National Institutes of Health Office of Research Infrastructure Programs Grant P40 0D010440.

Correspondence should be addressed to Jean-Louis Bessereau, Institut NeuroMyoGene, Université Claude Bernard Lyon 1, 16 rue R. Dubois, F-69622 Villeurbanne, France. E-mail: jean-louis.bessereau@univ-lyon1.fr.

DOI:10.1523/JNEUROSCI.3733-15.2016

Copyright $\odot 2016$ the authors $\quad 0270-6474 / 16 / 366525-13 \$ 15.00 / 0$
}

though they represent a significant fraction of the total amount of receptors expressed by the cells. In extreme cases, such as in striated muscle cells, the concentration of acetylcholine receptors (AChRs) at vertebrate neuromuscular junctions (NMJs) is 1000 times higher in synaptic than in extrasynaptic regions, whereas the pool of extrasynaptic receptors represents $99 \%$ of the total amount of receptors present at the plasma membrane of muscle fibers (Salpeter and Loring, 1985).

At the synapse, specific cues, such as trans-synaptic interaction of adhesion molecules or activation of signaling cascades by presynaptic secreted factors, trigger the clustering of scaffolding molecules and the recruitment of receptors. The nonclustered distribution of extrasynaptic receptors is generally seen as a default state reflecting the absence of neurally derived clustering. However, extrasynaptic receptor clusters are often detected in diverse nonmature systems. For instance, in neuronal primary cultures, as much as $80 \%$ of AMPA receptor clusters and $40 \%$ of GABA receptor clusters are not synaptic (Mammen et al., 1997; Danglot et al., 2003). In few cases, active mechanisms were demonstrated to cause the disappearance of these extrasynaptic clus- 
A

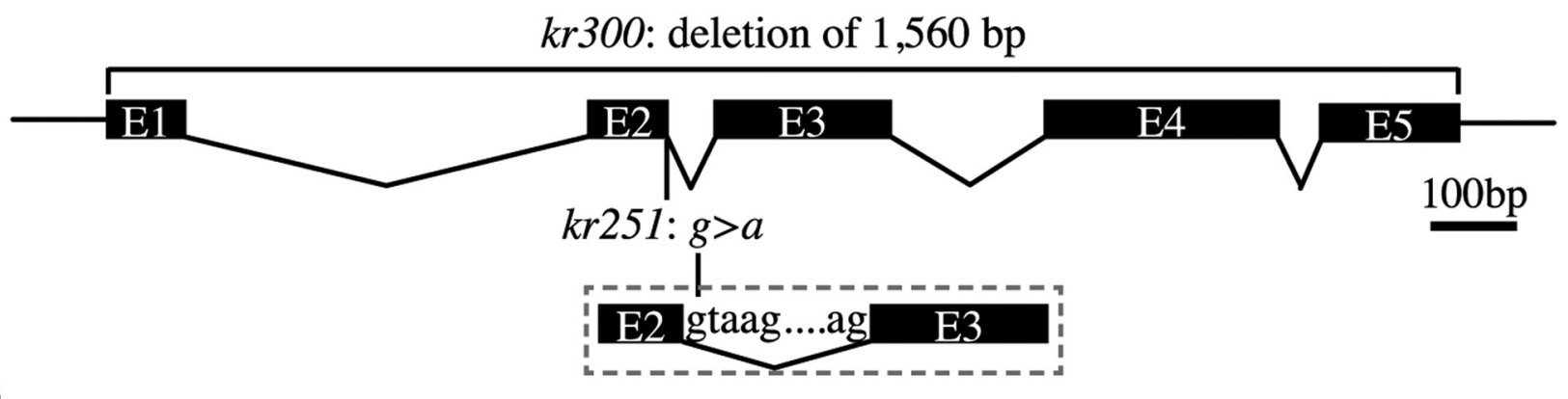

B

L-AChR (unc-29::tagRFP knock-in)
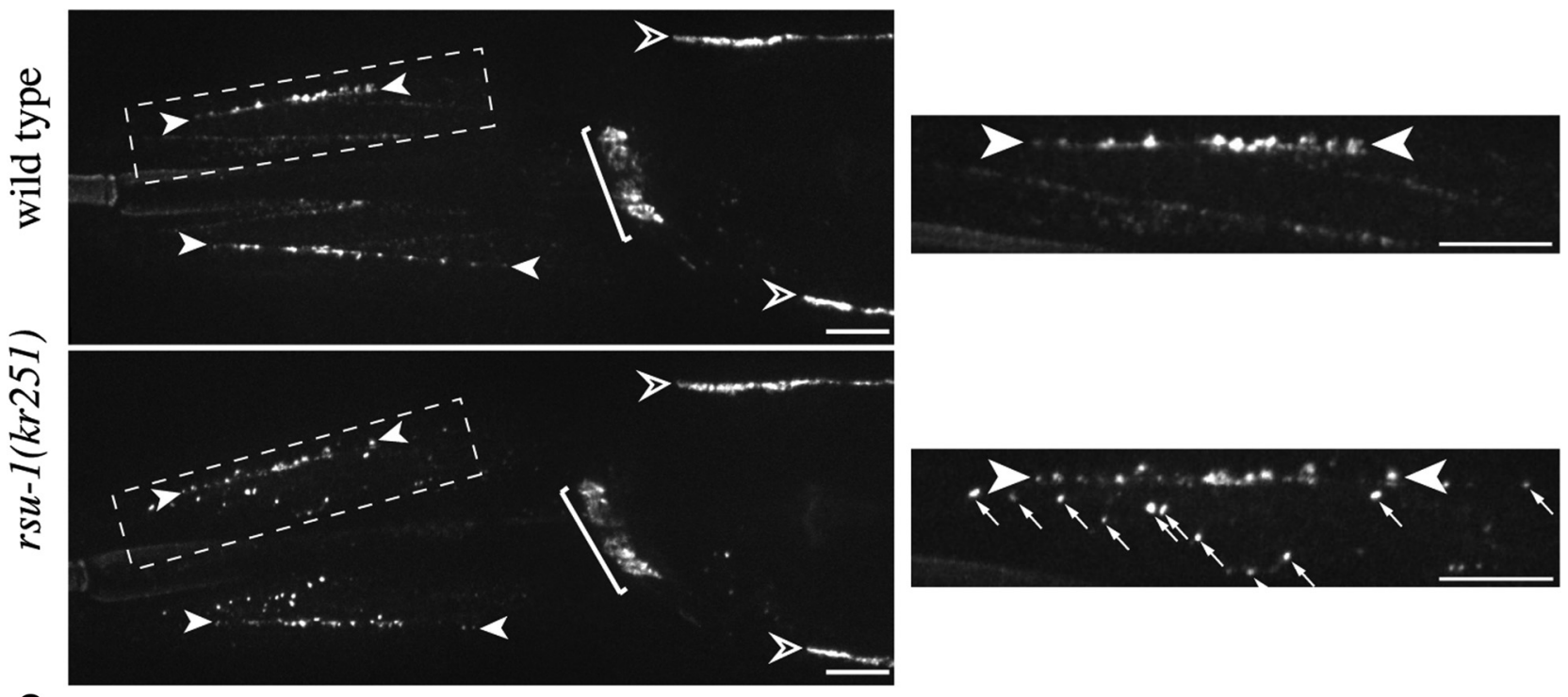

C

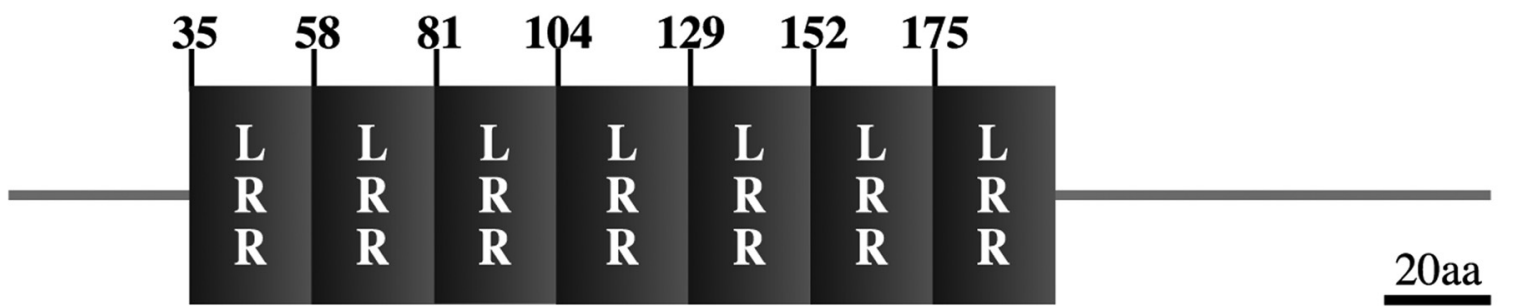

D

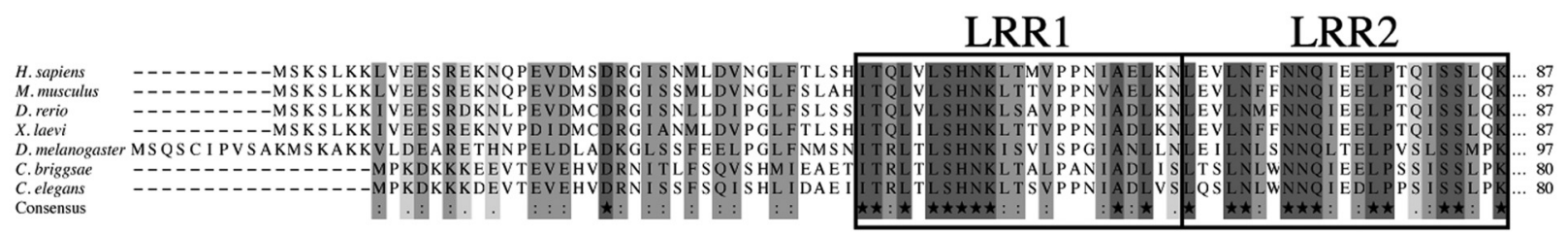

\begin{tabular}{|c|c|c|c|c|c|c|}
\hline $\begin{array}{c}\text { Percentage of } \\
\text { identity }\end{array}$ & $\begin{array}{c}\text { H. sapiens } \\
\text { RSU1_001 } \\
277 \text { aa }\end{array}$ & $\begin{array}{c}\text { M. musculus } \\
\text { Rsu1 } \\
277 \text { aa }\end{array}$ & $\begin{array}{c}\text { D.rerio } \\
\text { F1QL43 } \\
277 \text { aa }\end{array}$ & $\begin{array}{c}\text { X. laevi } \\
\text { Rsu1 } \\
277 \text { aa }\end{array}$ & $\begin{array}{c}\text { D. melanogaster } \\
\text { RSU-1 } \\
283 \text { aa }\end{array}$ & $\begin{array}{c}\text { C. briggsae } \\
\text { CBP02462 } \\
268 \text { aa }\end{array}$ \\
\hline $\begin{array}{c}\text { C.elegans } \\
\text { RSU-1 } \\
268 \text { aa }\end{array}$ & $56.02 \%$ & $55.64 \%$ & $55.26 \%$ & $54.51 \%$ & $51.52 \%$ & $89.55 \%$ \\
\hline
\end{tabular}

Figure 1. rsu-1 encodes a conserved LRR protein involved in L-AChR distribution. $A$, Structure of the rsu- 1 locus. Black boxes, Coding regions; vertical black line, point mutation; dashed rectangle, details of the point mutation; bracket, full deletion of the locus. B, Left column, Stitched confocal projections of the anterior region of wild-type and rsu-1(kr251) young adults. L-AChR clusters (unc-29::tagRFP knock-in) localize at NMJs at dorsal and ventral SABs (delimited by filled arrowheads), at dorsal and ventral nerve cords (open arrowheads), and at the nerve ring (bracket). Multiple ectopic clusters are observed between the rows of dorsal and ventral synaptic SAB clusters in rsu-1(kr251). Right column, Magnifications of the boxed regions (Figure legend continues.) 
ters. For example, the elimination of supernumerary AChR clusters during the regression of muscle polyinnervation depends on the neurotransmitter acetylcholine and the activation of the cyclin-dependent kinase-5 kinase (Lin et al., 2005). However, it is not clear whether active mechanisms are required to keep receptors diffuse in mature systems. To address this question, we used the Caenorhabditis elegans NMJs as a genetically tractable model system.

C. elegans hermaphrodites contain 95 body wall muscle (BWM) cells arranged in four quadrants along the ventral and dorsal sides of the worm. BWMs do not fuse, and each cell receives excitatory and inhibitory innervation from cholinergic and GABAergic motoneurons, respectively. Cholinergic and GABAergic motoneurons secrete different isoforms of the extracellular matrix protein $\mathrm{Ce}$-Punctin/MADD-4 that trigger the clustering of ionotropic $\mathrm{AChR}$ and type-A GABA receptors $\left(\mathrm{GABA}_{\mathrm{A}} \mathrm{Rs}\right)$ at distinct synaptic sites (Pinan-Lucarré et al., 2014; Tu et al., 2015). At cholinergic NMJs, levamisole-sensitive AChRs (L-AChRs) are activated by the nematode-specific cholinergic agonist levamisole and are heteropentameric (Fleming et al., 1997; Culetto et al., 2004; Towers et al., 2005). L-AChRs are localized at the synapse by interacting with an extracellular scaffold assembled in the synaptic cleft. This involves three proteins expressed by muscle cells: LEV-10, a type 1 transmembrane protein whose L-AChR clustering activity is contained in its ectodomain (Gally et al., 2004), and LEV-9 and OIG-4, which are processed and secreted by muscle cells (Gendrel et al., 2009; Rapti et al., 2011; Briseño-Roa and Bessereau, 2014). These proteins form a physical complex together with L-AChRs that is stabilized at cholinergic synapses through the long Ce-Punctin/MADD-4 isoforms secreted by cholinergic motoneurons (Pinan-Lucarré et al., 2014).

To identify additional components regulating L-AChR localization, we performed an unbiased screen for mutants with abnormal L-AChR distribution after chemical mutagenesis of a knock-in strain expressing fluorescent L-AChRs. We focused on NMJs made by SAB motoneurons in the head and isolated a mutant with large extrasynaptic clusters of L-AChRs. This strain contained a mutation in $r s u$ - 1 (ras suppressor 1), an evolutionarily conserved gene previously not characterized in C. elegans. The rsu-1 gene was initially isolated in mammalian cells because of its ability to suppress RAS-transformed phenotypes when overexpressed (Cutler et al., 1992). It codes for a cytoplasmic protein containing seven leucine-reach repeats (LRRs), which interacts with the IPP (Integrin linked kinase-PINCH-Parvin) complex in Drosophila and mammalian cells and regulates cell adhesion and migration (Kadrmas et al., 2004; Dougherty et al., 2005). Here we describe a previously unanticipated function of RSU-1 that points to the control of L-AChR dispersal in extrasynaptic regions of muscle cells.

\footnotetext{
(Figure legend continued.) emphasizing the presence of ectopic L-AChR clusters in rsu1(kr251) (arrows) compared with wild type. In this figure and all other figures, anterior is to the left and dorsal is up. Scale bars, $10 \mu \mathrm{m}$. C, Schematic domain structure of RSU-1. The position of the first residue of each LRR domains identified using LRR finder are indicated (Offord and Werling, 2013). Gray lines are regions with low complexity. D, Clustal Omega (EBI) alignment of the N terminus of RSU-1 orthologs from nematodes, fly, and vertebrates. The two first LRRs are boxed. Color code used to highlight residues is as follows: conserved residues in dark gray, residues with strongly similar properties (scoring $>0.5$ ) in medium gray, and residues with weakly similar properties (scoring $\leq 0.5$ ) in light gray. Percentages of identity between fulllength RSU-1 orthologs are presented in the table. Low complexity regions were included for evaluating percentages of identity.
}

\section{Materials and Methods}

C. elegans strains and media. All strains were raised at $20^{\circ} \mathrm{C}$ on nematode growing medium agar seeded with the Escherichia coli strain OP50 as a source of food using standard methods (Brenner, 1974). The wild-type reference strain was C. elegans N2 Bristol. Cohorts of synchronized L1, L2, and L3 larvae and young adults were obtained by egg laying of 20 gravid adults for $1 \mathrm{~h}$ at $20^{\circ} \mathrm{C}$ and were imaged after $15,25,33$, and $60 \mathrm{~h}$ of growth at $20^{\circ} \mathrm{C}$, respectively. Additionally, gonad morphology criteria were used to control worm larval stage before acquisition as follows: (1) L1 stage: two germ cells $\left(Z_{2}\right.$ and $\left.Z_{3}\right) ;(2)$ L2 stage: multiple germ cells in a single gonad; and (3) L3 stage: elongated gonads with anterior and posterior regions but the distal arms have not yet started to turn dorsally. For young adults, the distal arm extremities reached the vulva level on the dorsal side, and vulva has closed but no embryos were visible. For immunohistochemistry, large populations of synchronized young adults were obtained $60 \mathrm{~h}$ after egg preparation using bleaching of gravid adults.

The following mutant alleles and transgenes were used in this study: unc-29(kr208::tagRFP) (Richard et al., 2013), rsu-1(kr251), rsu-1(kr300), unc-97(su110) (Hobert et al., 1999), unc-112(r367) (Rogalski et al., 2000), unc-29::myc(kr244) (Boulin et al., 2012), lev-9::T7(kr184) (Gendrel et al., 2009), lev-9(ox177::Mos1) (Gendrel et al., 2009), lev-10(kr26::Mos1) (Gally et al., 2004), madd-4(kr249) (Pinan-Lucarré et al., 2014), unc-112 (st581); RaEx16[rol-6(su1006); unc-112(+)::GFP] (Rogalski et al., 2000),

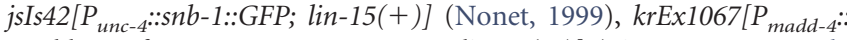

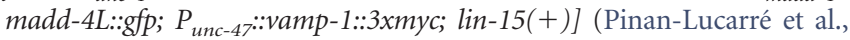

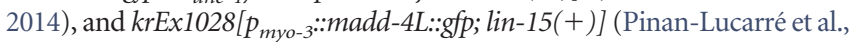
2014).

The following transgenic lines were created for this study in unc-29(kr208::tagRFP); rsu-1(kr251): krEx1162, krEx1163, and krEx1164 [pMP11; pIP1302B]; krEx1165, krEx1166, and krEx1167 [pMP13;pIP1302B]; krEx1174, krEX1175, and krEx1176 [pMP16; pIP1302B]; krEx1206[pKG156; pIP1302B]; krEx1207, krEx1208, krEx1209, and krEX1210 [pMP12; pIP1302B].

Molecular biology and germ-line transformation. Standard techniques were used to generate expression constructs [Gateway (Invitrogen) and Gibson ligation (Gibson, 2011)] and transgenic animals (Mello et al., 1991). Details of templates and specific PCR primers for promoters and genes amplification used to generate expression constructs are available on request.

To build the $r s u-1$ transcriptional reporter pMP11: $P_{r s u-1}:: r s u-1 g$ DNA::SL2:::gfp::3' $U T R_{\text {unc-54 }}$, a genomic fragment of 3825 bp was PCR amplified from N2 genomic DNA using Q5 polymerase (New England Biolabs) with primers comprising tails containing NotI and Sgfl restriction sites. After enzymatic restriction of the PCR product and $\mathrm{pBP} 1$ vector, $r s u-1$ genomic DNA was cloned into pBP1 SL2-GFP containing vector at NotI and SgfI restriction sites.

Tissue-specific constructs were generated by Gateway cloning (Invitrogen). rsu- 1 cDNA was obtained by RT-PCR on mixed-stage nematodes RNA extracts, subcloned by pJet cloning, reamplified with attB sites containing oligos, and inserted by BP reaction into the pDONR221 backbone. LR reactions were used to generate pMP13: $P_{\text {myo-3 }}:: r s u-1 c D N A:: 3^{\prime} U T R_{\text {unc-54 }}$ and pMP16: $P_{\text {rab-3 } 3}:: r s u-1 c D N A:: 3^{\prime} U T R_{u n c-54}$. In these vectors, promoter fragments were given by pBP15 (myo-3 promoter derived from pmyo-3[4-1]; a gift from M. Hammarlund, Department of Genetics and Program in Cellular Neuroscience, Neurodegeneration and Repair, Yale University School of Medicine, New Haven, CT) and pEGB05 ( $r a b-3$ promoter; a gift from E. Jorgensen, Howard Hughes Medical Institute, Department of Biology, University of Utah, Salt Lake City, UT). The unc-54 3' UTR ENTRY vector was a gift from M. Hammarlund.

The following vectors were generated using Gibson assembly with $40 \mathrm{bp}$ overlapping sequences for recombination between adjacent PCR products and/or opened backbone. The green fluorescent protein (GFP) tag was inserted at the C-terminal end: pMP12:Prsu-1::rsu-1gDNA:::gfp::3'UTR unc-54 $_{\text {, }}$ pMP19: $P_{\text {eft-3 }}::$ cas $9:: 3^{\prime} U T R_{t b b-2}:: P_{U 6}::: s g R N A r s u-1$, and pMP20:LHR::I-SceI::

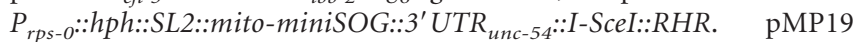
and pMP20 constructs are detailed below (see Generation of $r s u-1$ deletion allele using CRISPR and transgene-instructed gene conversion). pKG156: $P_{m y o-3}:: g p i:: Y F P$ is a kind gift from Laura Pierson (CGphiMC, Université Lyon 1, Lyon, France). Transgenic lines were generated by coinjection of 
expression constructs at $10-20 \mathrm{ng} / \mu \mathrm{l}$ with the transformation marker pIP1302B at $50 \mathrm{ng} / \mu \mathrm{l}$ along with $1 \mathrm{~kb}$ ladder as a carrier DNA (New England Biolabs) up to $100 \mathrm{ng} / \mu \mathrm{l}$. pIP1302B was built by Pablo Ibáñez-Cruceyra (Institut de Biologie de l'Ecole Normale Supérieure, Paris, France) and used as a coinjection marker. It encodes the $E$. coli hygromycin resistance gene $h p h$, under the control of the ribosomal promoter $P_{r p s-0 .}$. After injection, worms were individually picked onto fresh plates. When F1s started to lay eggs, $30 \mu \mathrm{l}$ of hygromycin B (in PBS at $50 \mathrm{mg} / \mu \mathrm{l}$; Invitrogen) was added on the surface of plates to positively select transgenic worms.

Generation of rsu-1 deletion allele using CRISPR and transgene-instructed gene conversion. The rsu-1 (kr300) molecular null allele was generated using CRISPR-Cas9 and transgene-instructed gene conversion as described previously (Dickinson et al., 2013). The entire coding sequence of $r s u-1$ was replaced with a cassette containing a positive selection marker.

To target Cas9 to the rsu-1 genomic locus, we inserted the 5'gtaggcgcaggcgcaggcgc3' 19 bp targeting sequence into the Cas9-sgRNA construct (pDD162) opened with SphI and NarI using Gibson assembly.

Homologous repair template (pMP20) for cassette insertion was built in two phases using Gibson assembly and restriction/ligation. First, we PCR-amplified $1.5 \mathrm{~kb}$ left (LHR) and right (RHR) homology sequences from N2 gDNA using reverse-LHR and forward-RHR oligos with $40 \mathrm{bp}$ tails containing I-SceI restriction sites. Together with a DNA fragment containing AmpR gene and ColE1 origin, PCR products were circularized using Gibson assembly (RHR/LHR vector). The selection cassette flanked by I-SceI sites was inserted in the LHR/ RHR vector by restriction/ligation. It contains the resistance gene to hygromycin $\mathrm{B}(h p h)$ drive by a ribosomal promoter $\left(P_{r p s-0}\right)$.

An injection mix containing $50 \mathrm{ng} / \mu \mathrm{l}$ targeting vector (pMP19), $50 \mathrm{ng} / \mu \mathrm{l}$ homologous repair template (pMP20), $5 \mathrm{ng} / \mu \mathrm{l}$ pPD118.33 $\left(P_{\text {myo-2 }}: \because g f p\right.$ pharyngeal muscles coinjection marker), $20 \mathrm{ng} / \mu \mathrm{l} \mathrm{pBP5}$ ( $P_{\text {ser- }-:: g f p}$ head muscles coinjection marker), and $10 \mathrm{ng} / \mu \mathrm{l}$ pMA122 (heat-shock driven PEEL-1-negative selection) was microinjected into the gonads of unc-29(kr208::tagRFP) young adults. After injection, single worms were picked to fresh plates and maintained at $25^{\circ} \mathrm{C}$ until starvation $(10-12 \mathrm{~d})$. Four days after injection, after F1s started to lay eggs, $30 \mu$ l of hygromycin B (in PBS at $50 \mathrm{mg} / \mu \mathrm{l}$; Invitrogen) was added on the surface of the plates to positively select transgenic worms. After starvation, worms were heat shocked at $34^{\circ} \mathrm{C}$ for $2 \mathrm{~h}$ in a water bath to activate PEEL-1-negative-selection marker, which kills animals carrying extrachromosomal arrays. After $6 \mathrm{~h}$ recovery at room temperature, plates were chunked and placed at $25^{\circ} \mathrm{C}$ overnight. Plates were visually screened to identify those containing healthy and nonfluorescent animals. From these plates, worms presenting the $r s u-1$ mutant phenotype based on UNC-29-tagRFP fluorescence pattern were individually picked and single-copy insertion of the cassette at the $r s u-1$ locus was confirmed by PCR.

Antibody injection. Detection of L-AChR at the surface of muscle cells by antibody injection was performed as described previously (Boulin et al., 2012). In brief, worms with unc- 29 genomic locus modified by the addition of three myc tag sequences were injected into the pseudocolomic cavity with anti-c-myc-Cy3 antibodies (C6594; Sigma-Aldrich) di-
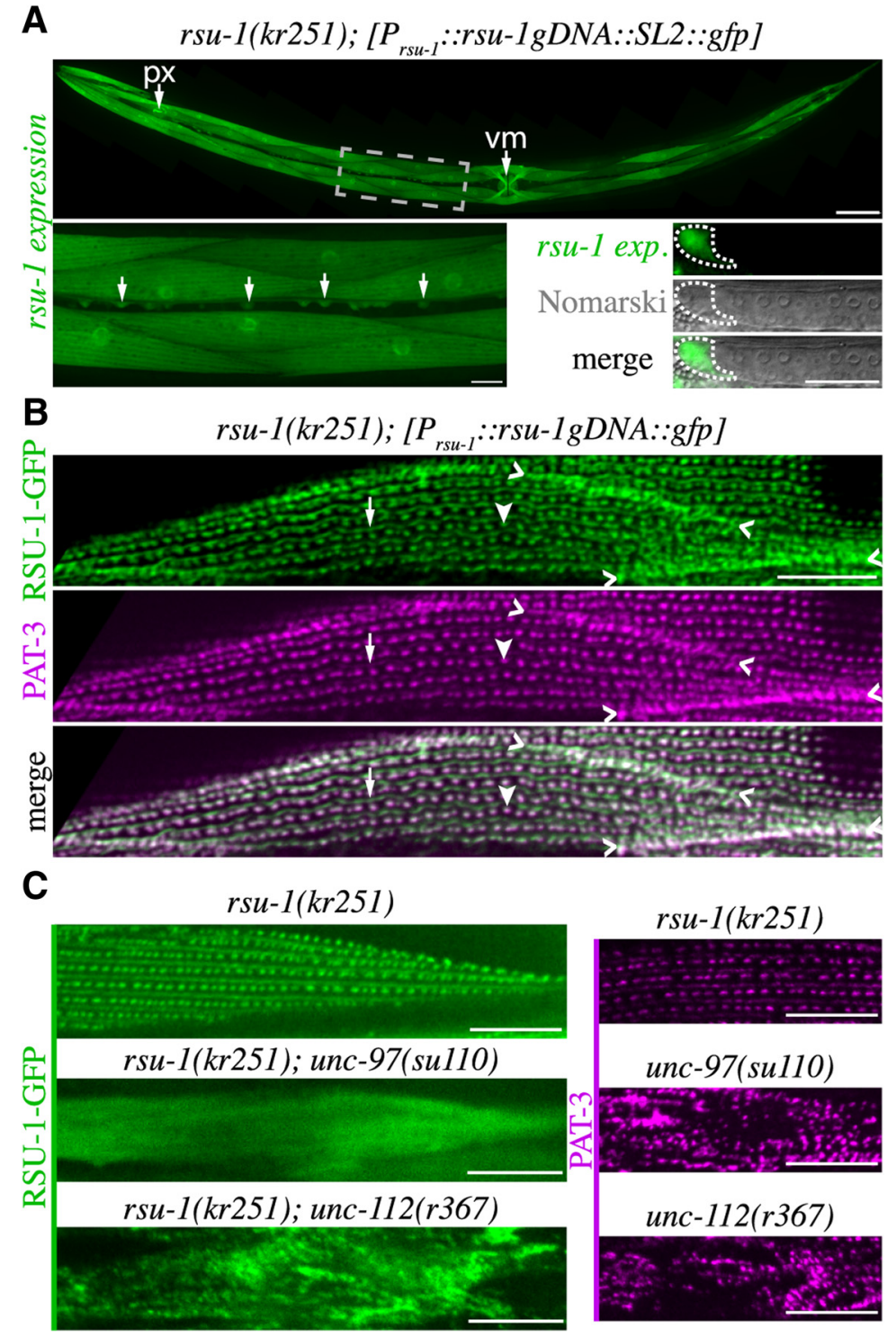

Figure 2. RSU-1 localizes in muscles at integrin adhesion complexes by interacting with UNC-97/PINCH. $\boldsymbol{A}$, Top, An artificial can be seen at higher magnification. Bottom right, GFP is also observed in the gonad distal tip cell (highlighted with white ( (one is shown by an arrowhead), M-lines (one is shown by an arrow), and intercellular junctions (between thin arrowheads). $C$ RSU-1-GFP (left) and PAT-3 (right) distributions in young adults of different genetic backgrounds. RSU-1-GFP observations and anti-PAT-3 immunostainings were performed on different animals. Scale bars, $10 \mu \mathrm{m}$.

luted 200-fold in injection buffer $\left(20 \mathrm{mM} \mathrm{K}_{2} \mathrm{HPO}_{4}, 3 \mathrm{mM} \mathrm{K}{ }^{+}\right.$citrate, and $2 \%$ PEG 6000, pH 7.5). Worms were imaged 6-7 h after injection.

Immunofluorescence staining. Immunohistochemistry was performed as described previously (Gendrel et al., 2009). In brief, synchronized young adults were washed in ice-cold M9, freeze-cracked, fixed in acetone/methanol or in $4 \%$ paraformaldehyde when using anti-T7 antibodies, and collected in $1 \times$ PBS. Samples were blocked for $30 \mathrm{~min}$ at room temperature with $0.2 \%$ fish gelatin. A mix of primary or secondary antibodies was incubated at $4^{\circ} \mathrm{C}$ overnight. Primary antibodies were used at the following dilutions: rabbit polyclonal anti-GFP (A11122; Invitrogen), 1:500; mouse monoclonal anti-PAT-3 MH25, 1:100 (Francis and Waterston, 1985), monoclonal anti-DEB-1 MH24, 1:200 (Francis and Waterston, 1985), rabbit polyclonal anti-UNC-38, 1:500 (Gendrel et al., 2009), monoclonal anti-T7 (Novagen), 1:500; rabbit polyclonal antiUNC-49, 1:500 (Gendrel et al., 2009), and mouse monoclonal anti- 


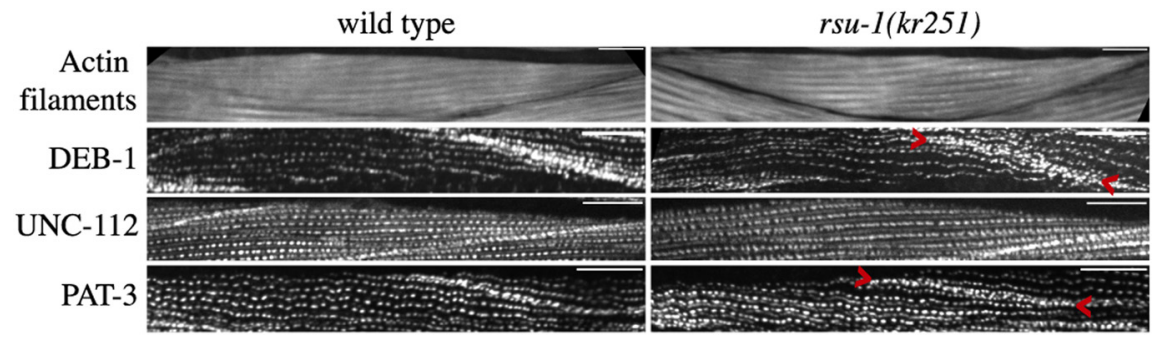

Figure 3. RSU-1 is not essential for integrin adhesion complexes assembly. Actin filaments, DEB-1/vinculin, UNC-112/fermitin, and PAT-3/ $\beta$-integrin distributions in wild-type and $r$ su- 1 (kr251) mutant adults. Actin, DEB-1, and PAT-3 were visualized using phalloidin-rhodamine staining and immunodetection with MH24 and MH25 antibodies, respectively. For UNC-112/fermitin, unc-112(st581) and rsu-1(kr251); unc-112(st581) expressing the raEx16[rol 6(su 1006); unc 112(+)::GFP] rescuing transgene were observed. Red brackets delimit intercellular adhesion plaques that are less packed in rsu-1(kr251) compared with wild type. Scale bars, $10 \mu \mathrm{m}$.

VAChT/UNC-17, 1:11000 (Gally et al., 2004). Secondary antibodies were all used at 1:500 and included Alexa Fluor 488-labeled goat anti-rabbit IgG (Molecular Probes A-11008; Invitrogen), Alexa Fluor 488-labeled goat anti-mouse IgG (Molecular Probes A-11001; Invitrogen), Cy3labeled goat anti-mouse IgG (Jackson ImmunoResearch A10521; Invitrogen), Cy3-labeled goat anti-rabbit IgG (Jackson ImmunoResearch A10520; Invitrogen), and Dylight 649-conjugated goat anti-rabbit IgG (111-495-144; Jackson ImmunoResearch). To label actin filaments, worms fixation and phalloidin-rhodamine staining were performed as described previously (Waterston et al., 1984).

Microscopy. Animals were mounted on 2\% agarose pads and anesthetized with $10 \mu \mathrm{l}$ of sodium azide at $100 \mathrm{~mm}$ in M9 buffer. Worms were examined using an inverted confocal microscope (Olympus IX83) equipped with a CSU spinning disk (Yogokawa) and an EMCCD camera (iXon ultra 888) driven by Andor IQ3.3 software, except for images of $r s u-1$ expression in the gonad distal tip cell in Figure $2 A$ that were acquired using a fluorescent microscope (Axioskop Zeiss) equipped with a Nomarski prism and a CoolSnap HQ2 camera driven by Micromanager1.3 software. Image reconstruction and merges were obtained with $\mathrm{NIH}$ Image $J$ except for stitched images in Figures $1 B$ and $2 A$ (top) that were generated using the plugin "pairwise stitching of images" of Fiji (Preibisch et al., 2009). All images shown are maximum intensity projections of $Z$-stacks $0.8-17 \mu \mathrm{m}$ deep, except Figures $4, D$ and $F$, and $10 B$ that are sum intensity projections. In Figures $4, C$ and $E, 6 A, 7 A, 8,9$, and $10 A$, background was subtracted with the Subtract Background tool of NIH Image J (different rolling ball radius used).

Image quantification. Quantification of synaptic L-AChRs at SABs (see Figs. $4 D, 10 B$ ) or at the dorsal cord (see Fig. $4 F$ ) in the unc-29 (kr208::tagRFP) knock-in background was achieved by following a previously published protocol, which was initially described for in vivo labeling with anti-myc-Cy3 (Boulin et al., 2012). Fluorescence levels were measured for the entire SAB process (one SABD or SABV per imaged worm) or for the anteriormost $30 \mu \mathrm{m}$ portion of the dorsal cord. Analysis was performed on two (see Figs. 4F, 10B) and three (Fig. 4D) different days. For each genetic background, Shapiro-Wilk test controlled the normality of distribution. The lack of significant difference between data obtained from independent experiments was tested by two-tailed Student's $t$ tests before pooling data together. Data are presented as the mean fluorescence \pm SEM. Two-tailed Student's $t$ tests were performed to compare different genotypes.

To evaluate the number of ectopic L-AChR clusters in the head during development (see Fig. 6), the same maximum and minimum gray values were applied for both genotypes at a given stage and the "red-hot" lookup table was used to emphasize signal intensity variations. Aggregates of L-AChR in extrasynaptic areas, according to the non-apposition with jsIs42 presynaptic marker, and presenting a fluorescence level similar to that of synaptic clusters were counted as ectopic clusters. $Z$-stacks covering the entire head depth were analyzed.

\section{Results \\ $r s u-1$ was identified in a visual screen for abnormal L-AChR distribution}

To identify synaptic organizers controlling the formation of excitatory synapses, we performed a visual screen for abnormal L-AChR distribution (Pinan-Lucarré et al., 2014). We used a knock-in strain in which the red fluorescent protein tagRFP was introduced into the genomic locus of the obligatory L-AChR subunit unc-29, in a nonconserved region of the large intracellular M3-M4 loop (Robert and Bessereau, 2007; Richard et al., 2013). In this strain, UNC-29-tagRFP accurately localizes at cholinergic NMJs as visualized by in vivo epifluorescence. By screening worms mutagenized with ethyl methane sulfonate, we isolated the mutant allele $k r 251$ on the basis of multiple ectopic L-AChR clusters in the head region (Fig. $1 A, B$ ). The causal mutation was identified in the rsu-1 locus by whole genome sequencing and confirmed using fosmid rescue experiments. Sequencing data revealed a G-to-A transition in the splicing donor site of the second intron (Fig. 1A). As a consequence, a premature stop codon is introduced upstream of the last three exons. To obtain a complete loss-of-function allele, $k r 300$, we generated a full deletion of the locus using CRISPR-Cas9 and transgene-instructed gene conversion. The two alleles had a similar phenotype, suggesting that $k r 251$ is a strong loss-of-function allele (Fig. $1 A$ and data not shown).

To confirm C. elegans genome annotations, we sequenced rsu-1 cDNAs. rsu-1 mRNA is trans-spliced to the Splice Leader SL1 upstream of the start codon, and we found no evidence for alternative splicing. $r s u-1$ encodes a 268 aa solenoid protein conserved among metazoans (Fig. $1 C, D$ ). It contains seven LRRs, domains of 23-26 aa defined by the 11-residues hallmark sequence LxxLxLxxNxL (Kajava, 1998). Tandem of LRRs adopts a curved shape with a parallel $\beta$ sheet on the concave face and with a variety of secondary structures, such as $\alpha$ helix, on the convex face (Enkhbayar et al., 2004). Most if not all LRR proteins appear to be involved in protein-protein interactions with the concave face being the most likely binding region (Bella et al., 2008).

$r s u-1$ has not been analyzed so far in C. elegans and is identified here as a new regulator of L-AChR localization.

\section{RSU-1 localizes at integrin adhesion complexes in muscle by interacting with UNC-97/PINCH}

To monitor $r s u$ - 1 expression pattern in the worm, a GFP coding sequence preceded by an SL2 splice leader acceptor site was added to $r s u-1$ genomic fragment. This bicistronic vector drives the expression of $r s u-1$ and the $g f p$ reporter in the same cells under the control of $r s u-1$ regulatory sequences. GFP was detected from embryonic to adult stages (Fig. $2 A$ and data not shown). In adults, $r s u-1$ was found expressed in somatic BWMs and in nonstriated pharyngeal and vulval muscles. It was also detected in a subset of neurons of the ventral cord, in the gonad distal tip cells, and, in some transgenic lines, in epithelial cells.

To determine the subcellular localization of the RSU-1 protein, a C-terminally tagged RSU-1-GFP fusion protein was expressed under the control of $r s u$ - 1 regulatory sequences. This rescuing translational reporter revealed a similar set of expressing cells except for the epithelial cells that were not detected. In 
BWMs, RSU-1 was located at cell boundary structures called "adhesion plaques" and to discrete spots and lines that likely overlapped with dense bodies and M-lines, respectively (Fig. 2B, top). The dense bodies and M-lines attach the myofilament lattice to the muscle cell membrane. The presence of RSU-1 at these muscle adhesion sites was confirmed by its colocalization with PAT-3/ $\beta$-integrin in double-labeling experiments using anti-GFP and anti-PAT-3/ $\beta$-integrin antibodies (Fig. 2B). These data are consistent with previous reports in Drosophila and mammalian cells that showed an interaction of Rsul with the IPP complex, which regulates focal adhesion (FA) formation via binding of the adaptor protein ILK to $\beta$-integrin (Gonzalez-Nieves et al., 2013).

In Drosophila and cultured mammalian cells, Rsul interacts through its LRR domain with the fifth LIM domain (LIM5) of PINCH (particularly interesting new cysteine-histidine rich protein; Kadrmas et al., 2004; Dougherty et al., 2005). Consistently, yeast two-hybrid assays predicted a physical interaction between RSU-1 and UNC-97, the C. elegans PINCH ortholog (Li et al., 2004; Simonis et al., 2009). To determine whether RSU-1 binding to the myofilament attachment sites requires UNC-97/PINCH, we monitored RSU-1-GFP in unc-97(su110) hypomorphic mutant. su110 allele is a $\mathrm{G}>\mathrm{A}$ splice site mutation at the last intronexon boundary of the unc-97 locus, which is predicted to only disrupt the structural integrity of the LIM5 domain (Hobert et al., 1999; Norman et al., 2007). In this mutant context, RSU-1-GFP failed to localize to the attachment structures and was instead observed in a diffuse pattern throughout the muscle cell cytoplasm (Fig. $2 C$, left). Because integrin complexes are fully disorganized in unc-97(su110), we monitored RSU-1-GFP pattern in unc112(r367) hypomorphic mutant, another mutant context that also leads to integrin disorganization (Fig. 2C, right; Norman et al., 2007). UNC-112/fermitin is a scaffolding protein involved in integrin signaling pathways that is required for the assembly of FA complexes (Rogalski et al., 2000). In this case, RSU-1-GFP still localizes to adhesion sites, although they were abnormally distributed. These data indicate that UNC-97/PINCH is required for RSU-1 to localize at integrin adhesion sites, potentially through a conserved interaction between RSU-1 and the fifth LIM domain of UNC-97.

Previous studies highlighted the striking similarity between vertebrate FAs and C. elegans muscle adhesion structures (Cox and Hardin, 2004). In C. elegans, mutations in muscle adhesion genes cause severe defects ranging from embryonic developmen-

E

$\mathbf{F}$

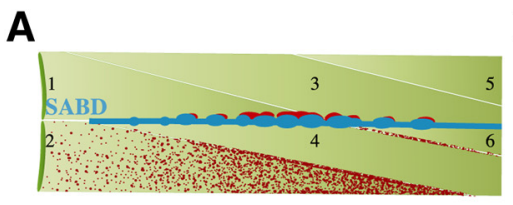

B
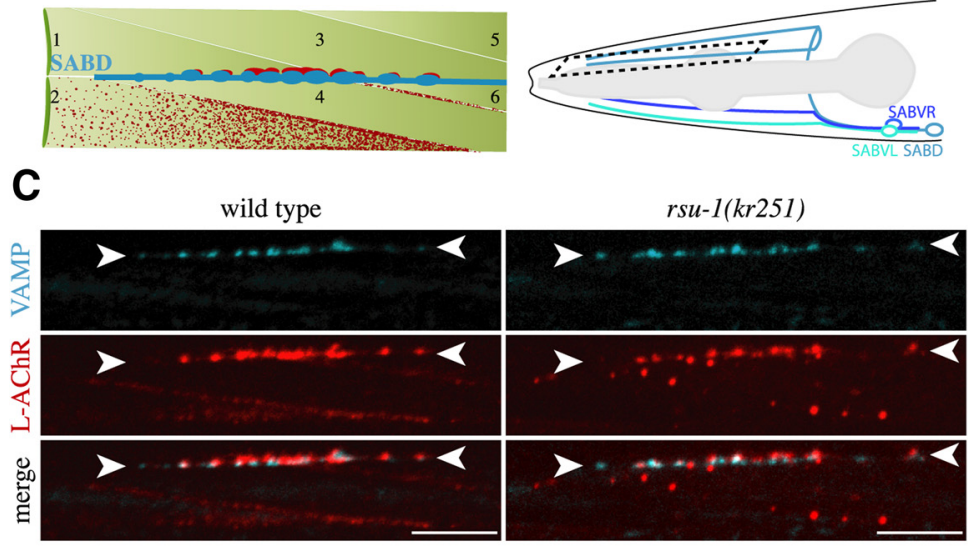

D L-AChR fluorescence (\% of wild type)

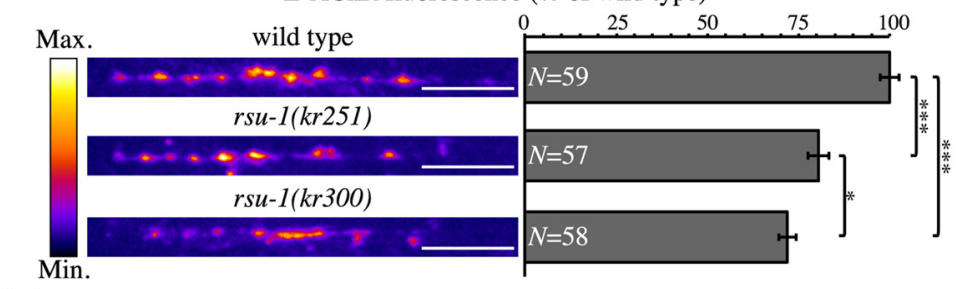

wild type

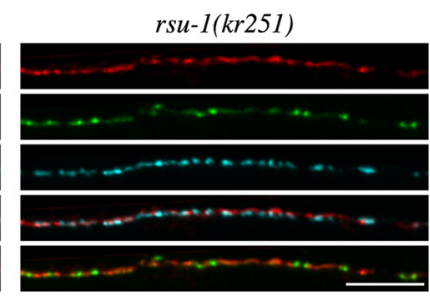

L-AChR fluorescence (\% of wild type)

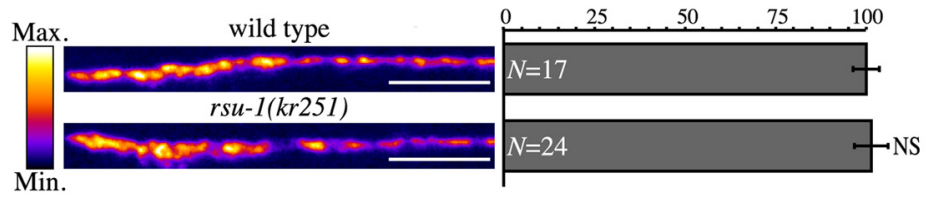

Figure 4. Illegitimate clustering of extrasynaptic L-AChRs in rsu-1 mutant. $\boldsymbol{A}$, Diagram highlighting the position of an SABD axon relative to the most anterior muscle cells of a dorsal quadrant. Muscle cells (green) are numbered according to their position in the quadrant. SABD, Cyan; L-AChRs, red. $B$, Schematic of C. elegans head region. SABVR, SABVL, and SABD are shown in different shades of blue. The pharynx is shown in gray. Dashed rectangle matches with the region in $A$. $C$, Confocal projections of the SABD region of wild-type and $r s u-1$ (kr251) young adults expressing a presynaptic marker (VAMP, jsis42[punc-4::snb-1::GFP]) and the L-AChR reporter (unc-29::tagRFP knock-in). Synaptic clusters are apposed to presynaptic varicosities (between arrowheads). In the wild type, diffused extrasynaptic receptors cover muscle cell 2 and the intercellular junction between muscle cells 4 and 6 (see also A). In rsu-1 (kr251), aggregates of L-AChRs are visualized in extrasynaptic areas. D, Quantification of UNC-29-tagRFP fluorescence levels at SAB synapses in the wild-type and rsu- 1 mutants. $\boldsymbol{E}$, Labeling of cholinergic terminal (VAChT, anti-UNC-17 immunofluorescence), L-AChRs (persistent unc-29::tagRFP fluorescence after fixation), and GABA $A_{A}$ Rs (anti-UNC-49 immunofluorescence) at the dorsal cord in wild-type and rsu-1(kr251) young adults. $\boldsymbol{F}$, Synaptic clustering of L-AChRs (unc-29::tagRFP knock-in) was evaluated at the dorsal cord in wild-type and rsu-1(kr251) young adults. Quantification data are presented as means \pm SEM; $N$ indicates number of worms; Student's tests between genotypes: ${ }^{*} p \leq 0.05 ;{ }^{* * *} p \leq 0.001$; NS, not significant. Scale bars, $10 \mu \mathrm{m}$.

tal arrest (the Pat phenotype: paralyzed and arrested elongation at twofold) for null mutants to lethargic behaviors for hypomorphic mutations (Hobert et al., 1999; Mackinnon et al., 2002; Lin et al., 2003). However, $r s u-1(k r 300)$ null mutants are viable, do not present any obvious locomotory defect, and are slightly egglaying defective, as manifested by an accumulation of eggs in the gonad (data not shown). RSU-1 subcellular localization prompted us to analyze the structural integrity of the muscle attachment structures in $r s u$ - 1 background. To this end, we examined the subcellular localization of defined components of muscle focal junctions using 
A

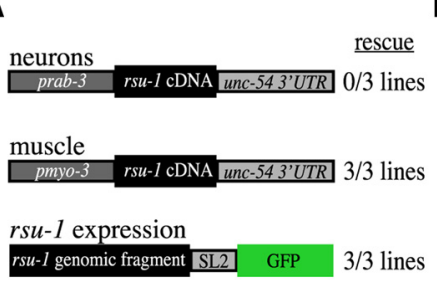

rsu-1 subcellular localization rsu-I genomic fragment $\quad$ GFP $3 / 3$ lines
B

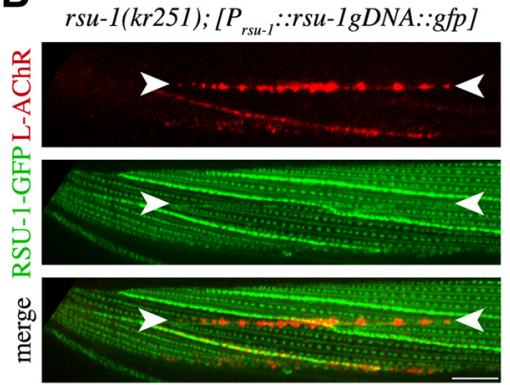

Figure 5. RSU-1 functions in muscle to prevent illegitimate clustering of extrasynaptic L-AChRs. A, Transgenic lines were generated for the different transgenes (not drawn to scale) in the rsu-1(kr251) background. Rescue was established based on both the absence of ectopic L-AChR clusters and the presence of diffused extrasynaptic L-AChR. The two last constructs were used to determine the rsu- 1 expression pattern and RSU-1 subcellular localization detailed in Figure 2, A and $B$. B, Confocal projections of the SABD region of an $r s u-1(\mathrm{kr} 251)$ young adult expressing the L-AChR reporter and RSU-1-GFP fusion protein. Scale bars, $10 \mu \mathrm{m}$.

either translational reporters or immunofluorescence staining. We compared the distribution of actin filaments, DEB-1/ vinculin, UNC-112/fermitin, and PAT-3/ $\beta$ integrin, in wild-type and $r s u-1(k r 251)$ adults (Fig. 3). Muscle attachment structures in the mutant context were indistinguishable from wild type except at intercellular junctions, in which they appeared slightly less packed. Altogether, these observations suggest that $r s u-1$ is not essential for the assembly of integrin complexes, in agreement with results obtained in cell cultures and flies (Kadrmas et al., 2004; Dougherty et al., 2005).

A

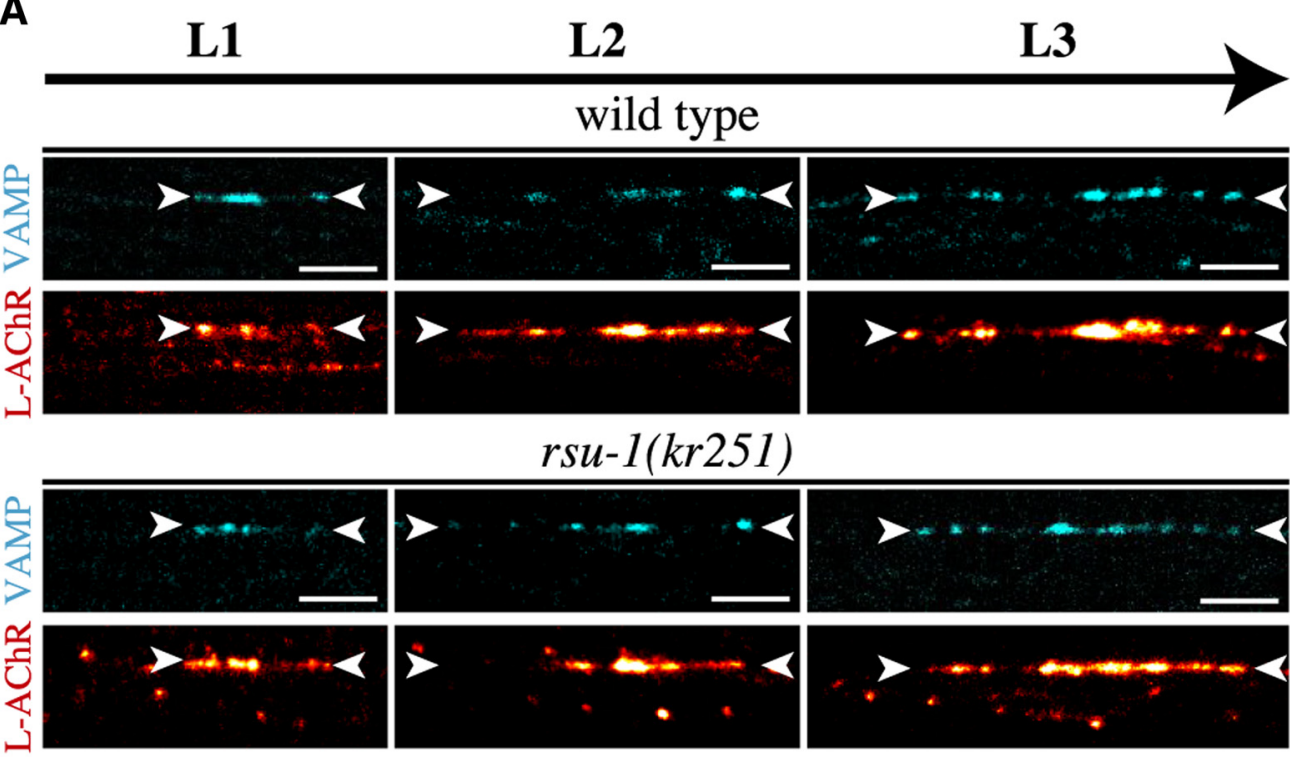

B
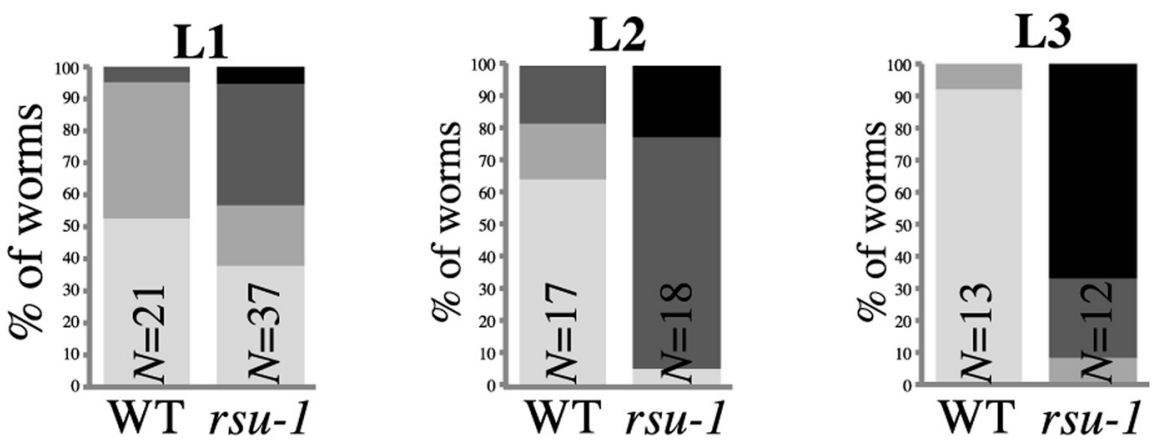

$$
\begin{gathered}
\text { number of ectopic clusters (ec) per worm: } \\
\square \text { ec }=0 \square \text { ec }=1 \square 1<\text { ec } \leq 10 \square \text { ec }>10
\end{gathered}
$$

Figure 6. L-AChR ectopic clusters form progressively during development in rsu-1 mutant. A, Confocal projections of the SABD region of wild-type and rsu- 1 (kr251) animals at L1, L2, and L3 stages expressing a presynaptic marker (VAMP, jsls42[punc-4::snb-1::GFP]) and the L-AChR reporter (unc-29::tagRFP). Synaptic clusters are between arrowheads. Ectopic L-AChR clusters with a fluorescence level similar to synaptic clusters are detected in $r s u-1$ ( $k$ r251) larvae. Scale bars, $5 \mu \mathrm{m}$. B, Proportion of wild-type and $r s u-1(\mathrm{kr} 251)$ animals at each stage presenting zero, one, between one and 10, or $>10$ ectopic clusters. Nindicates the number of worms. The red-hot look up table was applied on full stacks covering the entire head width, and ectopic clusters were counted when reaching a level of fluorescence similar to that of synaptic clusters. 
RSU-1 is required in muscle cells to prevent the formation of $\mathrm{L}-\mathrm{AChR}$ clusters in extrasynaptic regions of the muscle membrane

Multiple ectopic L-AChR clusters were observed in the head of the $r s u-1(k r 251)$ mutant. In this region, head muscle cells are innervated by the cholinergic SAB neurons. The three SAB cell bodies are located in the retrovesicular ganglion, ventral to the posterior bulb of the pharynx (Fig. $4 A, B$ ). These neurons project their axons anteriorly between the two rows of each muscle cell quadrant. Each of the two ventral SABs (SABVL and SABVR) innervates cells in a single ventral quadrant, whereas the dorsal SABD axon bifurcates. Each process innervates four cells in each quadrant and makes 15-20 NMJs (Fig. 4A; Zhao and Nonet, 2000; Kratsios et al., 2015). To determine whether $r s u-1$ ectopic clusters might be at ectopic synapses, we visualized SAB presynaptic boutons using the vesicle-associated membrane protein (VAMP) fused to GFP (Nonet, 1999). In the wild type, L-AChR clusters were apposed to cholinergic presynaptic domains. Some extrasynaptic receptors were detected at the intercellular junction between muscle cells 4 and 6 . Interestingly, diffuse receptors were visualized on the whole surface of the most anterior muscle cell (number 2), which is not innervated by $\mathrm{SAB}$ axons (Fig. $4 C$, left and refer to scheme in $A)$. In $r s u-1(k r 251)$, L-AChR clusters were readily detected in front of SAB boutons, although the quantification of synaptic fluorescence indicates a 30\% decrease of synaptic receptor content (Fig. $4 C, D)$. Large ectopic clusters were also pres-

ent in extrasynaptic regions. Noteworthy, the diffuse extrasynaptic receptors present in the wild type were no longer observed in $r s u-1$ mutants. These observations suggested that $r s u-1$ ectopic clusters might result from the aggregation of diffuse extrasynaptic L-AChR.

We also analyzed NMJs at the dorsal and ventral nerve cords. In these regions, BWMs extend dendrite-like cellular processes called muscle arms that reach the neural cords and elongate along the motoneurons to make en passant synapses. Cholinergic presynaptic and postsynaptic domains were in register, and $\mathrm{GABA}_{\mathrm{A}} \mathrm{R}$ clusters were intercalated between excitatory synapses in $r s u-1$ mutant as in the wild type (Fig. $4 E$ ). In addition, no extrasynaptic L-AChR clusters were observed, and L-AChR synaptic content was unchanged in $r s u-1$ ( $k r 251)$ (Fig. 4F).

To determine in which cell types $r s u$ - 1 expression is required for accurate L-AChR distribution, we expressed $r s u-1$ under the control of either the BWM-specific promoter, $P_{\text {myo-3 }}$, or a pan-neuronal promoter, $P_{\text {rab-3 }}$ (Fig. 5A). The $\mathrm{L}$-AChR phenotype was only rescued in transgenic $r s u-1 \mathrm{mu}-$ tant lines expressing $r s u-1$ in muscle cells (three of three lines). Thus, $r s u-1$ functions cell autonomously in muscles for L-AChR distribution. In addition, the $r s u$ - 1 expression reporter, $P_{r s u-1}:: r s u-1 g D N A:: S L 2:: g f p$, and the $r s u-1$ translational reporter, $P_{r s u-1}:: r s u-1 g D N A:: g f p$, used above (Fig. $2 A, B$ ) were as efficient for phenotype rescue. Using this reporter, we ob-

C wild type
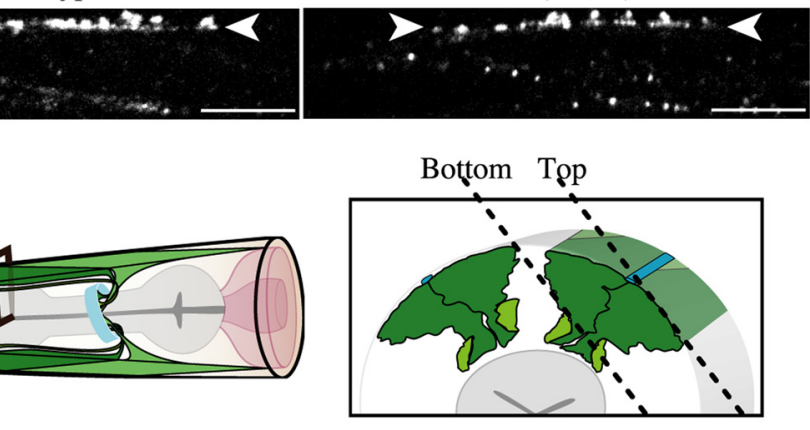

Figure 7. $\quad$ rsu-1 ectopic L-AChR clusters are properly inserted in the plasma membrane and mainly localize in muscle arms. $\boldsymbol{A}$, 作 point to rsu-1(kr251) ectopic L-AChR clusters colocalized with muscle arm membrane. Arrowheads delimit the synaptic region.

served that RSU-1-GFP and L-AChRs do not colocalize at the muscle cell membrane in neither synaptic nor extrasynaptic regions (Fig. 5B), suggesting an indirect role for RSU-1 in regulating L-AChR distribution.

\section{L-AChR ectopic clusters form progressively during development in rsu-1 mutant}

Extrasynaptic L-AChR clusters observed in adults might result from either a progressive aggregation of L-AChR during development or defective maintenance of L-AChR clustering in adults. To distinguish between these hypotheses, we analyzed synapse formation at SABs from hatching to the third larval stage. In the wild type, synaptic L-AChR clusters that are facing presynaptic domains were observed at the first larval stage, and their intensity increased over development (Fig. 6A). In addition, few nonsynaptic clusters were detected in approximately half of the wild-type L1 larvae whereas they were absent in L3 larvae, indicating a maturation of SAB NMJs during development (Fig. 6B). In rsu$1(k r 251)$, synapse formation appeared normal. However, in $>50 \%$ of the mutants analyzed at first larval stage, from 1 to 10 ectopic clusters were detected in head muscle cells. Throughout larval stages 1 to 3, the percentage of worms exhibiting extrasynaptic clusters increased as did the number of ectopic clusters per worm (Fig. 6A,B). These results suggested that, in the absence of 
A

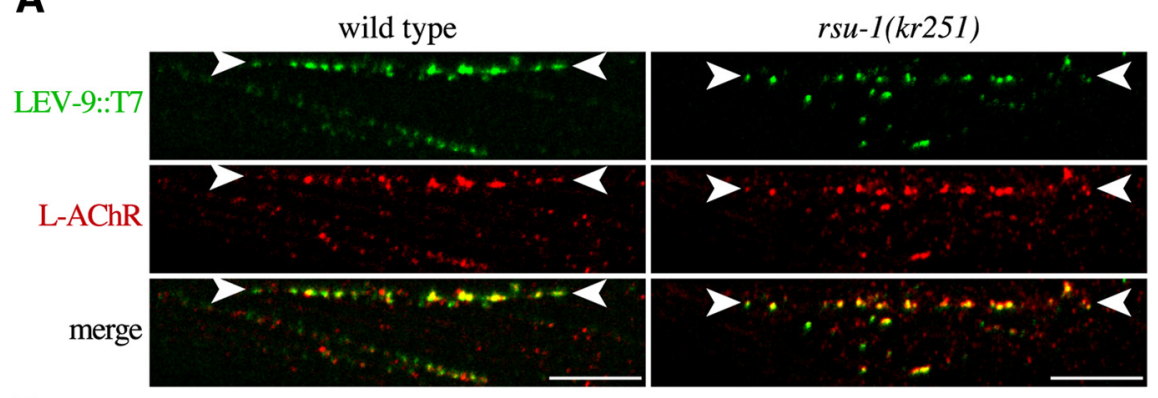

B

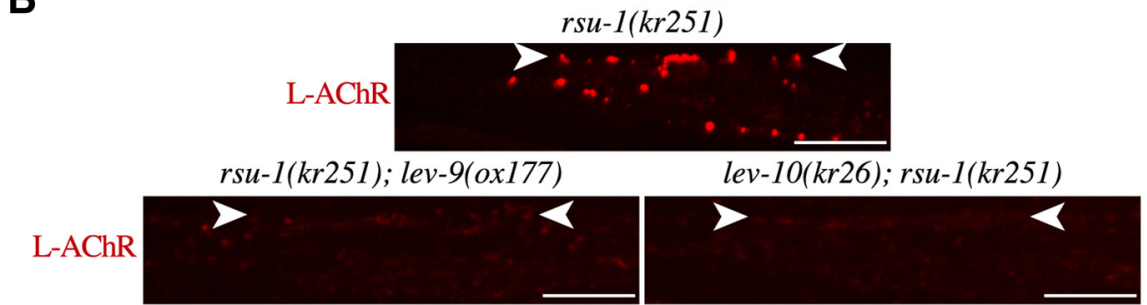

C

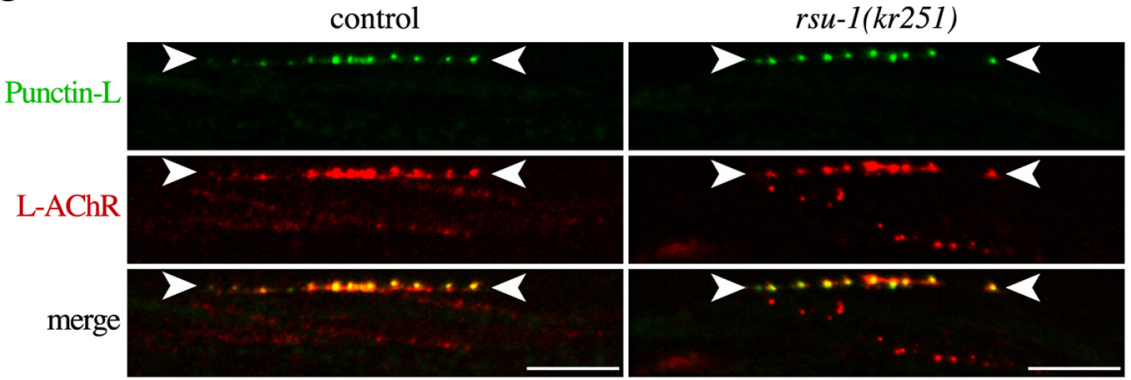

Figure 8. Ectopic L-AChR clusters result from the auto-assembly of the L-AChR associated scaffold. $A$, Confocal projections of the SABD region of fixed wild-type and rsu-1 (kr251) young adults. Immunofluorescence staining of LEV-9::T7 using anti-T7 antibodies and of L-AChRs using anti-UNC-38 antibodies. The LEV-9 scaffolding protein colocalizes with rsu-1 (kr251) ectopic L-AChR clusters. B, L-AChR distribution (unc-29::tagRFP knock-in) in the same region of single and double mutants. rsu-1(kr251) synaptic and ectopic L-AChR clusters are not observed in the double-mutant contexts. C, Confocal projections of the SABD region of control and rsu-1(kr251) young adults expressing the L-AChR reporter in a madd-4(kr249) background rescued by expression of Ce-Punctin long isoforms fused to GFP. Ce-Punctin-L localization is not impaired and is restricted to synapses in the rsu- 1 mutant. Arrowheads delimit the synaptic region. Scale bars, $10 \mu \mathrm{m}$.

RSU-1, receptors are progressively trapped in extrasynaptic clusters. This might preclude their proper recruitment at SAB synapses, hence leading to a diminished content in adult synapses as shown above (Fig. 4D).

L-AChR ectopic clusters are properly addressed to the muscle cell membrane of $r s u-1$ mutants and localize in muscle arms To test whether ectopic L-AChR clusters were properly localized at the plasma membrane or might be retained in intracellular compartments, we used a knock-in strain expressing an UNC-29 L-AChR subunit with an extracellular myc tag at its C terminus (Boulin et al., 2012). Fluorescently labeled anti-myc antibodies injected into the pseudocœelomic cavity of live unc-29::myc worms can only stain receptors inserted in the plasma membrane (Gottschalk and Schafer, 2006). In the wild type, both synaptic clusters and extrasynaptic diffused receptors were detected (Fig. 7A, left). In $r s u$-1 (kr251) mutant, synaptic and ectopic clusters were both detected, indicating that L-AChRs in the ectopic clusters are also correctly inserted in the plasma membrane (Fig. $7 A$, right). However, we noticed that most of them were not in the same focal plane as synaptic clusters. Therefore, we labeled muscle cell membranes by expressing a GPIanchored yellow fluorescent protein (YFP) under a muscle-specific promoter. Although synaptic L-AChRs are found at the external face of the muscle cells below the cuticle (Fig. $7 B, C$, top planes), most ectopic clusters were at the inner face of the muscle cells in contact with the coelomic cavity (Fig. $7 B, C$, bottom planes). Interestingly, muscle arms emanate from this side of the cells to extend toward the nerve ring, in which they form NMJs with a distinct set of head motoneurons. In $r s u-1$ mutants, ectopic L-AChRs seem to localize on the initial segments of muscle arms.

\section{Ectopic L-AChR clusters result from the auto-assembly of the L-AChR-associated scaffold}

We previously demonstrated that LEV-9 or LEV-10 scaffolding proteins are essential for the clustering of synaptic L-AChR (Gally et al., 2004; Gendrel et al., 2009). These proteins form a complex with L-AChRs. Loss of any of the scaffolding molecule or of the L-AChR causes a complete disruption of the complex. To determine whether ectopic clusters formation in $r s u-1$ (kr251) mutant involved the scaffolding machinery, we analyzed LEV-9 distribution. In the wild type, LEV-9 colocalized with synaptic clusters and diffusely distributed receptors in extrasynaptic areas (Fig. 8A, left). In $r s u-1$ (kr251) mutant, LEV- 9 colocalized with both synaptic and extrasynaptic L-AChR clusters (Fig. 8A, right). To test whether LEV-9 was required for the formation of ectopic clusters, we built an rsu-1(kr251); lev9 (ox177) double mutant. Inactivation of lev-9 caused a complete disappearance of synaptic and extrasynaptic L-AChR clusters (Fig. 8B). A similar result was obtained when $l e v-10$ was genetically disrupted. Therefore, the clustering of L-AChR at ectopic sites requires the same scaffolding machinery as clustering at NMJs.

Localization of L-AChR associated complexes depends on $\mathrm{Ce}$ Punctin/MADD-4, an extracellular matrix protein secreted by motoneurons that localize in the synaptic cleft (Pinan-Lucarré et al., 2014). Ectopic L-AChR clusters might result from abnormal Punctin distribution. To test this possibility, we observed Punctin long isoforms in $r s u-1$ mutants. Punctin was only detected at synaptic sites, as in the wild type (Fig. $8 C$ ). In a complementary approach, we inactivated Ce-punctin/madd-4 in wild-type and rsu-1 backgrounds. In madd-4(kr249) null mutant, synaptic L-AChR clusters were no longer detected and only diffuse extrasynaptic receptors remained, as previously shown (Fig. 9; PinanLucarré et al., 2014). Strikingly, inactivation of madd-4 in $r s u$-1 (kr251) strongly enhanced the $r s u$-1 phenotype with the appearance of bigger and more numerous extrasynaptic L-AChR clusters and a complete loss of synaptic clusters (Fig. 9). First, these data indicate that the generation of ectopic clusters in $r s u-1$ mutants does not depend on Punctin. Second, they suggest that, in the wild-type situation, there is a dynamic equilibrium between receptors clustered at the synapse and diffuse extrasynaptic receptors. In the absence of RSU-1, the pool of extrasynaptic receptors assembles into illegitimate clusters. In punctin mutants, 
the disappearance of synaptic clusters would increase the pool of receptors available for extrasynaptic clustering and therefore enhances the $r s u$ - 1 phenotype.

We then investigated the role of integrin signaling in preventing nonsynaptic L-AChR cluster formation using unc97(su110) and unc-112(r367) hypomorphic mutants. In these mutants, multiple defects were previously described, including disorganization of integrin complexes, abnormal muscle arm migration, and impaired axonal outgrowth (Hobert et al., 1999; Rogalski et al., 2000; Alexander et al., 2009; Yang et al., 2014). Because of these multiple defects, it was difficult to conclude whether the presence of some nonsynaptic L-AChR clusters could be compared with what was observed in rsu-1 mutants (Fig. 9, left column). Thus, we took advantage of the phenotypic enhancement triggered by the absence of Punctin to determine whether nonsynaptic L-AChR clustering is increased in unc-97 and unc-112 mutants. We clearly observed nonsynaptic L-AChR clusters in the madd-4(kr249); unc-97(su110) double mutant, whereas no synthetic phenotype was observed in the madd-4(kr249); unc-112(r367) background (Fig. 9, right column). These results support that extrasynaptic L-AChRs clustering does not depend on FA complexes organization and strongly suggests that UNC-97/PINCH likely acts via RSU-1 to prevent illegitimate clustering of L-AChRs.

\section{Synaptic and extrasynaptic receptor pools compete with each other}

The $r s u$-1 phenotypic enhancement observed during Punctin depletion suggests that the competition between synaptic and extrasynaptic clusters might account for the decreased content of L-AChRs at SAB NMJs in $r s u-1$ mutants (Fig. 4D). To indirectly test this hypothesis, we ectopically expressed Punctin in muscle cells to create artificial extrasynaptic clusters in a wild-type background (Fig. 10A; Pinan-Lucarré et al., 2014). Despite normal expression of Punctin by SAB motoneurons, the amount of L-AChRs found at NMJs was decreased by half in transgenic animals (Fig. 10B), suggesting that the overall complement of $\mathrm{L}-\mathrm{AChR}$ expressed by the muscle cell remained constant and that ectopic clusters did compete with synaptic sites for the recruitment of L-AChRs.

Altogether, these data demonstrate that dispersal of extrasynaptic receptors is not a default state. Modifying the distribution of extrasynaptic receptors can subsequently affect synaptic receptor content.

\section{Discussion}

Our visual screen identified the intracellular protein RSU-1 as a new regulator of L-AChR distribution in muscle cells. RSU-1 was evolutionarily conserved, and, as in Drosophila and mammalian cells, it interacts with an integrin effector complex. Genetic depletion of RSU-1 in muscle causes illegitimate clustering of the wild type

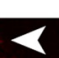

4

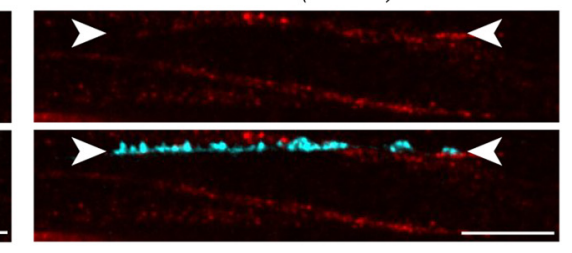

$r s u-1(k r 251)$

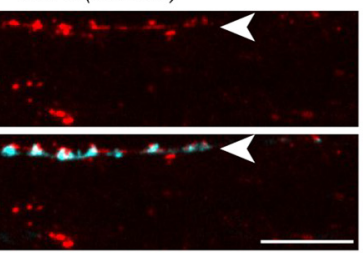

unc-97(su110)

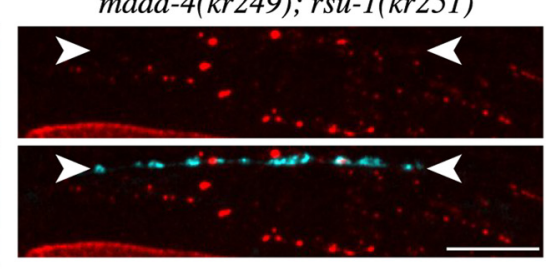

madd-4(kr249); unc-97(su110)

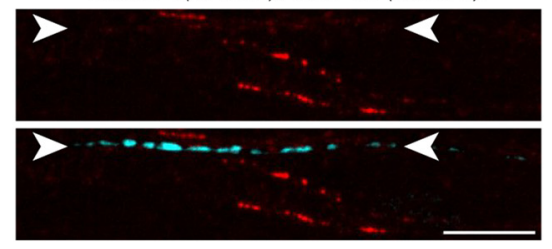

unc-112(r367)

madd-4(kr249); unc-112(r367)

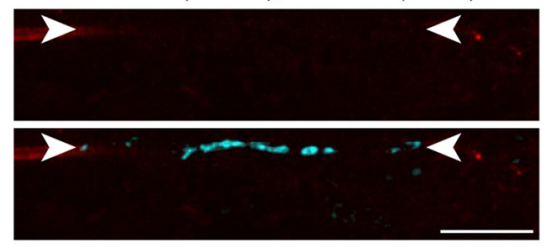

egitimate clustering of extrasynaptic L-AChRs. Confocal projections of the SABD region of young adults expressing a presynaptic marker (VAMP, js/s42[punc-4::snb-1::GFP]) and the L-AChR reporter (unc-29::tagRFP) in different genetic backgrounds. Synaptic clusters are between arrowheads. Scale bars, $10 \mu \mathrm{m}$.

extrasynaptic L-AChRs, which are dispersed in the wild type. In rsu-1 mutants, ectopic clusters compete with synaptic clusters, which causes a subsequent decrease of L-AChR content at synapses. Such phenotype was not reported previously. Therefore, our results indicate that the dispersed distribution of L-AChRs outside of the synapse is not a "default state" and that mechanisms involved in the maintenance of extrasynaptic receptor dispersion might consequently control synaptic strength.

$r s u-1$ has been well conserved during evolution, and the $C$. elegans gene is the clear ortholog of the Drosophila and vertebrate counterparts. We provide here the first characterization of an $r s u-1$ mutant in the nematode. The phenotype is very subtle with no obvious developmental or behavioral abnormality, except a slight egg-laying defect that we did not investigate further. Interestingly, our ability to recover an $r s u-1$ mutant in a forward screen strategy solely relied on the sensitivity of the visual screen for abnormal localization of AChR in vivo. Specifically, $r s u-1 \mathrm{mu}-$ tants are sensitive to the drug levamisole and would have been missed in traditional screens for resistance to levamisole. This subtle phenotype is consistent with what was observed in the fly icarus (ics) mutants in which Rsul is disrupted. These mutants are viable and fertile but only display some wing blisters characteristic of a failure of integrin-dependent adhesion. A recent work reports that $i c s$ flies also have abnormal ethanol consumption (Ojelade et al., 2015).

Drosophila and mammalian Rsul localize at FA sites via a physical interaction with the LIM5 domain of the adaptor protein PINCH (Kadrmas et al., 2004; Dougherty et al., 2005). PINCH is 
A

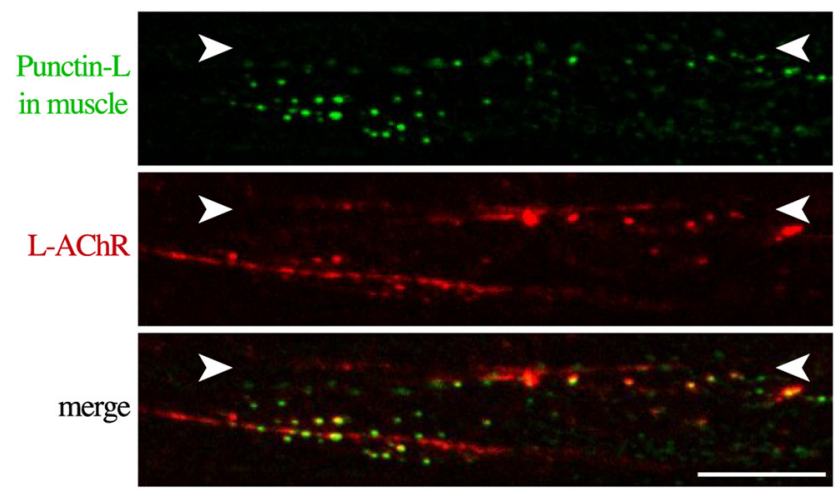

B

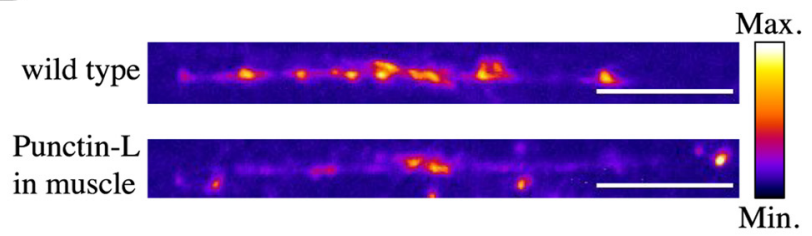

L-AChR fluorescence (\% of wild type)

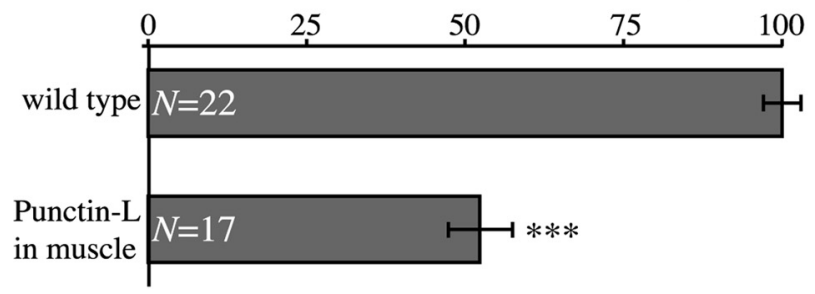

Figure 10. Ectopic L-AChR clusters compete with synaptic sites for L-AChR recruitment. $\boldsymbol{A}$, Confocal projections of the SABD region of an adult nematode expressing Ce-Punctin long isoforms fused to GFP in muscle cells and the L-AChR reporter (unc-29::tagRFP knock-in). Artificial expression of Ce-Punctin-L in muscles $\left(P_{\text {myo-3: }}\right.$ : $)$ unctin- $\left.L-g f p\right)$ triggers $L-A C h R$ ectopic clustering. Arrowheads delimit the synaptic region. $B$, Fluorescence intensity of the UNC-29tagRFP at SAB synapses of wild-type and transgenic animals. Formation of ectopic L-AChR clusters depletes synaptic L-AChR content. Results are presented as means \pm and SEMs; $N$ indicates the number of worms; Student's $t$ tests: ${ }^{* * *} p \leq 0.001$. Scale bars, $10 \mu \mathrm{m}$.

one of the major components of the IPP complex. By linking the cytoskeleton to the extracellular matrix via the $\beta$ subunit of integrin heterodimers, this complex participates in many aspects of cell behavior and fate (Brakebusch and Fässler, 2003; Legate et al., 2006). Our results suggest that the Rsul/PINCH interaction is conserved in C. elegans. First, RSU-1 colocalizes with integrincontaining structures that have similar composition to FAs. Second, large-scale yeast two-hybrid screens identified an interaction between RSU-1 and UNC-97, the PINCH ortholog. Third, RSU-1 no longer localizes at integrin attachment structures in an unc-97 mutant expressing a protein with altered conformation of its fifth LIM domain. However, the role of RSU-1 at this complex is still controversial and likely depends on the cellular context. RSU-1 was reported to positively regulate the level of PINCH, which we did not observe in C. elegans. RSU-1 can be a positive effector of integrin signaling and antagonize JNK activity (Masuelli and Cutler, 1996; Kadrmas et al., 2004). Genetic analysis of ethanol consumption in the fly suggests that Rsul antagonizes integrin signaling because $i c s$ mutants have opposite phenotypes to mutants in genes encoding PINCH and $\beta$-integrin. This might be achieved by inhibition of Racl and subsequent destabilization of the actin cytoskeleton (Ojelade et al., 2015). Finally, Rsul can function independently from PINCH to activate the p38 map kinase pathway (Gonzalez-Nieves et al., 2013). Altogether, Rsul unambiguously participates in the control of cell adhesion and migration, but the existence of redundant pathways likely accounts for the moderate phenotypes observed in null mutants in vivo.

Our results link for the first time $r s u-1$ to the control of neurotransmitter receptor distribution. Genetic ablation of $r s u-1$ causes ectopic AChR clusters in the most anterior muscle cells that are innervated by SAB motoneurons. Why this phenotype is limited to these cells only is intriguing. NMJs made by SAB motoneurons have distinct features compared with NMJs made along the nerve cords, and the sensitivity of the SAB system was previously revealed in punctin mutants in which fragmented L-AChR clusters remained detectable near synaptic regions in muscle arms, whereas L-AChRs almost completely disappeared from SAB synapses. First, the SAB system is more plastic because inhibition of muscle activity causes a homeostatic stimulation of $\mathrm{SAB}$ outgrowth and an increased number of NMJs, which is not seen at the cords (Zhao and Nonet, 2000). RSU-1 might affect the overall activity of neuromuscular transmission, which might in turn have a deeper effect on anterior muscle cells. However, we do not favor this hypothesis because large extrasynaptic AChR clusters are not detected in mutants altering synaptic transmission or muscle activity. Second, L-AChR subunit composition might not be identical in anterior muscle cells compared with the posterior part of the animal. However, L-AChR clustering requires identical scaffolding molecules at all cholinergic NMJs, and we demonstrated that ectopic clustering depends on these molecules. Third, and probably most important, the topology of the synapses made by SAB neurons is distinct from NMJs at the cords. SAB neurons spread on the outer surface of the muscle cells and make en passant synapses. At the cords, muscle arms grow from the inner face of the muscle cells toward the cords or the nerve ring, in which they spread along the motoneurons and receive their innervation. Consequently, trafficking of the receptors might be different in anterior muscle cells, with more receptors being targeted to the outer face of the muscle cells in which the actomyosin system is anchored. Loss of RSU-1 might cause mistargeting or leak of L-AChRs from this compartment to the muscle arms that grow at the inner face. The tubular geometry of the muscle arms might increase the concentration of receptors in the membrane and favor illegitimate clustering. Alternatively, the composition and/or the environment of the muscle arms might allow abnormal clustering of the receptors.

Although RSU-1 is required for proper L-AChR distribution, it probably does not implicate a direct interaction between RSU-1 and L-AChRs because we never detected the colocalization of the two proteins despite looking carefully. The apparition of ectopic clusters might be an indirect consequence of RSU-1 loss. Loss of RSU-1 might modify the diffusive behavior of extracellular receptors in the membrane, for instance, by causing a slight reduction of cellular adhesivity or by inducing a change of the extracellular matrix composition, as observed in the liver when impairing the PINCH-Rsul complex (Donthamsetty et al., 2013). However, loss of RSU-1 does not cause a complete disorganization of the membrane because proteins such as UNC-36, a subunit of a voltage-dependent calcium channel, remain normally distributed in $r s u-1$ mutants (data not shown). Alternatively, the effect of RSU-1 might be mediated by the regulation of intracellular signaling because, in other systems, it was shown to modulate at least the JNK and the p38 MAP kinase pathways. However, we did not observe extrasynaptic clusters during JNK-1 depletion, and we showed that ectopic clustering relies on the 
components of the extracellular scaffold that we described at the NMJs and is so far entirely operating from the outside of the cell. Finally, RSU-1 can control the dynamics of the actin cytoskeleton, which is important at the vertebrate NMJ to localize AChR clusters (Dai et al., 2000; Shi et al., 2012). However, no evidence so far points to a direct role of the cytoskeleton in the organization of L-AChR clusters at the C. elegans NMJ. Isolating additional mutants with similar phenotypes as rsu-1 might help deciphering between these hypotheses.

Analysis of $r s u-1$ mutants exemplifies that the dispersed status of extrasynaptic receptors is not a default state that can only be explained by the absence of "clustering factors." Instead, pathological situations are able to unmask the propensity of receptors and associated scaffolding proteins to assemble supramolecular assemblies. In $r s u-1$ mutants, the formation of extrasynaptic clusters was progressive and seemed to compete with the normal synaptic maturation that leads to the progressive recruitment of receptors in synaptic domains. Because of the dynamic equilibrium between synaptic and extrasynaptic receptor pools (Akaaboune et al., 1999), the formation of ectopic clusters creates receptor traps that are able to subsequently deplete synaptic domains. Interestingly, $r s u-1$ is expressed in the neurons of Drosophila melanogaster, in which it participates in the control of ethanol consumption. This function might be conserved in humans based on genetic studies (Ojelade et al., 2015). Whether $r s u-1$ plays a role in synaptic plasticity by controlling the distribution of extrasynaptic neurotransmitter receptors is a tantalizing hypothesis.

\section{References}

Akaaboune M, Culican SM, Turney SG, Lichtman JW (1999) Rapid and reversible effects of activity on acetylcholine receptor density at the neuromuscular junction in vivo. Science 286:503-507. CrossRef Medline

Alexander M, Chan KK, Byrne AB, Selman G, Lee T, Ono J, Wong E, Puckrin R, Dixon SJ, Roy PJ (2009) An UNC-40 pathway directs postsynaptic membrane extension in Caenorhabditis elegans. Development 136: 911-922. CrossRef Medline

Bella J, Hindle KL, McEwan PA, Lovell SC (2008) The leucine-rich repeat structure. Cell Mol Life Sci 65:2307-2333. CrossRef Medline

Boulin T, Rapti G, Briseño-Roa L, Stigloher C, Richmond JE, Paoletti P, Bessereau JL (2012) Positive modulation of a Cys-loop acetylcholine receptor by an auxiliary transmembrane subunit. Nat Neurosci 15:13741381. CrossRef Medline

Brakebusch C, Fässler R (2003) The integrin-actin connection, an eternal love affair. EMBO J 22:2324-2333. CrossRef Medline

Brenner S (1974) The genetics of Caenorhabditis elegans. Genetics 77:71-94. Medline

Briseño-Roa L, Bessereau JL (2014) Proteolytic processing of the extracellular scaffolding protein LEV-9 is required for clustering acetylcholine receptors. J Biol Chem 289:10967-10974. CrossRef Medline

Cox EA, Hardin J (2004) Sticky worms: adhesion complexes in C. elegans. J Cell Sci 117:1885-1897. CrossRef Medline

Culetto E, Baylis HA, Richmond JE, Jones AK, Fleming JT, Squire MD, Lewis JA, Sattelle DB (2004) The Caenorhabditis elegans unc-63 gene encodes a levamisole-sensitive nicotinic acetylcholine receptor alpha subunit. J Biol Chem 279:42476-42483. CrossRef Medline

Cutler ML, Bassin RH, Zanoni L, Talbot N (1992) Isolation of rsp-1, a novel cDNA capable of suppressing v-Ras transformation. Mol Cell Biol 12: 3750-3756. CrossRef Medline

Dai Z, Luo X, Xie H, Peng HB (2000) The actin-driven movement and formation of acetylcholine receptor clusters. J Cell Biol 150:1321-1334. CrossRef Medline

Danglot L, Triller A, Bessis A (2003) Association of gephyrin with synaptic and extrasynaptic GABAA receptors varies during development in cultured hippocampal neurons. Mol Cell Neurosci 23:264-278. CrossRef Medline

Dickinson DJ, Ward JD, Reiner DJ, Goldstein B (2013) Engineering the
Caenorhabditis elegans genome using Cas9-triggered homologous recombination. Nat Methods 10:1028-1034. CrossRef Medline

Donthamsetty S, Bhave VS, Mars WM, Bowen WC, Orr A, Haynes MM, Wu C, Michalopoulos GK (2013) Role of PINCH and its partner tumor suppressor Rsu-1 in regulating liver size and tumorigenesis. PLoS One 8:e74625. CrossRef Medline

Dougherty GW, Chopp T, Qi SM, Cutler ML (2005) The Ras suppressor Rsu-1 binds to the LIM 5 domain of the adaptor protein PINCH1 and participates in adhesion-related functions. Exp Cell Res 306:168-179. CrossRef Medline

Enkhbayar P, Kamiya M, Osaki M, Matsumoto T, Matsushima N (2004) Structural principles of leucine-rich repeat (LRR) proteins. Proteins 54: 394-403. CrossRef Medline

Fleming JT, Squire MD, Barnes TM, Tornoe C, Matsuda K, Ahnn J, Fire A, Sulston JE, Barnard EA, Sattelle DB, Lewis JA (1997) Caenorhabditis elegans levamisole resistance genes lev-1, unc-29, and unc-38 encode functional nicotinic acetylcholine receptor subunits. J Neurosci 17:58435857. Medline

Francis GR, Waterston RH (1985) Muscle organization in Caenorhabditis elegans: localization of proteins implicated in thin filament attachment and I-band organization. J Cell Biol 101:1532-1549. CrossRef Medline

Gally C, Eimer S, Richmond JE, Bessereau JL (2004) A transmembrane protein required for acetylcholine receptor clustering in Caenorhabditis elegans. Nature 431:578-582. CrossRef Medline

Gendrel M, Rapti G, Richmond JE, Bessereau JL (2009) A secreted complement-control-related protein ensures acetylcholine receptor clustering. Nature 461:992-996. CrossRef Medline

Gibson DG (2011) Enzymatic assembly of overlapping DNA fragments. Methods Enzymol 498:349-361. CrossRef Medline

Gonzalez-Nieves R, Desantis AI, Cutler ML (2013) Rsul contributes to regulation of cell adhesion and spreading by PINCH1-dependent and - independent mechanisms. J Cell Commun Signal 7:279-293. CrossRef Medline

Gottschalk A, Schafer WR (2006) Visualization of integral and peripheral cell surface proteins in live Caenorhabditis elegans. J Neurosci Methods 154:68-79. CrossRef Medline

Hobert O, Moerman DG, Clark KA, Beckerle MC, Ruvkun G (1999) A conserved LIM protein that affects muscular adherens junction integrity and mechanosensory function in Caenorhabditis elegans. J Cell Biol 144: 45-57. CrossRef Medline

Kadrmas JL, Smith MA, Clark KA, Pronovost SM, Muster N, Yates JR 3rd, Beckerle MC (2004) The integrin effector PINCH regulates JNK activity and epithelial migration in concert with Ras suppressor 1. J Cell Biol 167:1019-1024. CrossRef Medline

Kajava AV (1998) Structural diversity of leucine-rich repeat proteins. J Mol Biol 277:519-527. CrossRef Medline

Kratsios P, Pinan-Lucarré B, Kerk SY, Weinreb A, Bessereau JL, Hobert O (2015) Transcriptional coordination of synaptogenesis and neurotransmitter signaling. Curr Biol 25:1282-1295. CrossRef Medline

Legate KR, Montañez E, Kudlacek O, Fässler R (2006) ILK, PINCH and parvin: the tIPP of integrin signalling. Nat Rev Mol Cell Biol 7:20-31. CrossRef Medline

Li S, Armstrong CM, Bertin N, Ge H, Milstein S, Boxem M, Vidalain PO, Han JD, Chesneau A, Hao T, Goldberg DS, Li N, Martinez M, Rual JF, Lamesch P, Xu L, Tewari M, Wong SL, Zhang LV, Berriz GF, Jacotot L, Vaglio P, et al. (2004) A map of the interactome network of the metazoan C. elegans. Science 303:540-543. CrossRef Medline

Lin W, Dominguez B, Yang J, Aryal P, Brandon EP, Gage FH, Lee KF (2005) Neurotransmitter acetylcholine negatively regulates neuromuscular synapse formation by a Cdk5-dependent mechanism. Neuron 46:569-579. CrossRef Medline

Lin X, Qadota H, Moerman DG, Williams BD (2003) C. elegans PAT-6/ actopaxin plays a critical role in the assembly of integrin adhesion complexes in vivo. Curr Biol 13:922-932. CrossRef Medline

Mackinnon AC, Qadota H, Norman KR, Moerman DG, Williams BD (2002) C. elegans PAT-4/ILK functions as an adaptor protein within integrin adhesion complexes. Curr Biol 12:787-797. CrossRef Medline

Mammen AL, Huganir RL, O’Brien RJ (1997) Redistribution and stabilization of cell surface glutamate receptors during synapse formation. J Neurosci 17:7351-7358. Medline 
Masuelli L, Cutler ML (1996) Increased expression of the Ras suppressor Rsu-1 enhances Erk-2 activation and inhibits Jun kinase activation. Mol Cell Biol 16:5466-5476. CrossRef Medline

Mello CC, Kramer JM, Stinchcomb D, Ambros V (1991) Efficient gene transfer in C. elegans: extrachromosomal maintenance and integration of transforming sequences. EMBO J 10:3959-3970. Medline

Nonet ML (1999) Visualization of synaptic specializations in live C. elegans with synaptic vesicle protein-GFP fusions. J Neurosci Methods 89:33-40. CrossRef Medline

Norman KR, Cordes S, Qadota H, Rahmani P, Moerman DG (2007) UNC97/PINCH is involved in the assembly of integrin cell adhesion complexes in Caenorhabditis elegans body wall muscle. Dev Biol 309:45-55. CrossRef Medline

Offord V, Werling D (2013) LRRfinder2.0: a webserver for the prediction of leucine-rich repeats. Innate Immun 19(4):398-402. CrossRef Medline

Ojelade SA, Jia T, Rodan AR, Chenyang T, Kadrmas JL, Cattrell A, Ruggeri B, Charoen P, Lemaitre H, Banaschewski T, Büchel C, Bokde AL, Carvalho F, Conrod PJ, Flor H, Frouin V, Gallinat J, Garavan H, Gowland PA, Heinz A, et al. (2015) Rsul regulates ethanol consumption in Drosophila and humans. Proc Natl Acad Sci U S A 112:E4085-E4093. CrossRef Medline

Pinan-Lucarré B, Tu H, Pierron M, Cruceyra PI, Zhan H, Stigloher C, Richmond JE, Bessereau JL (2014) C. elegans Punctin specifies cholinergic versus GABAergic identity of postsynaptic domains. Nature 511:466470. CrossRef Medline

Preibisch S, Saalfeld S, Tomancak P (2009) Globally optimal stitching of tiled 3D microscopic image acquisitions. Bioinformatics 25:1463-1465. CrossRef Medline

Rapti G, Richmond J, Bessereau JL (2011) A single immunoglobulindomain protein required for clustering acetylcholine receptors in C. elegans. EMBO J 30:706-718. CrossRef Medline

Richard M, Boulin T, Robert VJ, Richmond JE, Bessereau JL (2013) Biosynthesis of ionotropic acetylcholine receptors requires the evolutionarily conserved ER membrane complex. Proc Natl Acad Sci U S A 110:E1055E1063. CrossRef Medline

Robert V, Bessereau JL (2007) Targeted engineering of the Caenorhabditis elegans genome following Mos1-triggered chromosomal breaks. EMBO J 26:170-183. CrossRef Medline

Rogalski TM, Mullen GP, Gilbert MM, Williams BD, Moerman DG (2000) The UNC-112 gene in Caenorhabditis elegans encodes a novel component of cell-matrix adhesion structures required for integrin localization in the muscle cell membrane. J Cell Biol 150:253-264. CrossRef Medline

Salpeter MM, Loring RH (1985) Nicotinic acetylcholine receptors in vertebrate muscle: properties, distribution and neural control. Prog Neurobiol 25:297-325. CrossRef Medline

Shi L, Fu AK, Ip NY (2012) Molecular mechanisms underlying maturation and maintenance of the vertebrate neuromuscular junction. Trends Neurosci 35:441-453. CrossRef Medline

Simonis N, Rual JF, Carvunis AR, Tasan M, Lemmens I, Hirozane-Kishikawa T, Hao T, Sahalie JM, Venkatesan K, Gebreab F, Cevik S, Klitgord N, Fan C, Braun P, Li N, Ayivi-Guedehoussou N, Dann E, Bertin N, Szeto D, Dricot A, Yildirim MA, et al. (2009) Empirically controlled mapping of the Caenorhabditis elegans protein-protein interactome network. Nat Methods 6:47-54. CrossRef Medline

Towers PR, Edwards B, Richmond JE, Sattelle DB (2005) The Caenorhabditis elegans lev- 8 gene encodes a novel type of nicotinic acetylcholine receptor $\alpha$ subunit. J Neurochem 93:1-9. CrossRef Medline

Triller A, Choquet D (2005) Surface trafficking of receptors between synaptic and extrasynaptic membranes: and yet they do move! Trends Neurosci 28:133-139. CrossRef

Tu H, Pinan-Lucarré B, Ji T, Jospin M, Bessereau JL (2015) C. elegans punctin clusters GABAA receptors via neuroligin binding and UNC-40/DCC recruitment. Neuron 86:1407-1419. CrossRef Medline

Waterston RH, Hirsh D, Lane TR (1984) Dominant mutations affecting muscle structure in Caenorhabditis elegans that map near the actin gene cluster. J Mol Biol 180:473-496. CrossRef Medline

Yang Y, Lee WS, Tang X, Wadsworth WG (2014) Extracellular matrix regulates UNC-6 (netrin) axon guidance by controlling the direction of intracellular UNC-40 (DCC) outgrowth activity. PLoS One 9:e97258. CrossRef Medline

Zhao H, Nonet ML (2000) A retrograde signal is involved in activitydependent remodeling at a C. elegans neuromuscular junction. Development 127:1253-1266. Medline 